\title{
ENERgy SAVINGS AND STRUCTURAL CHANGES IN THE U.S. ECONOMY: EVIDENCE FROM DISAGGREGATED DATA USING DECOMPOSITION TECHNIQUES
}

\author{
Scott Murtishaw and Lee Schipper
}

September 2001

\author{
Energy Analysis Program \\ Environmental Energy Technologies Division \\ Lawrence Berkeley National Laboratory \\ University of California \\ Berkeley, CA 94720
}

This work was funded by the Office of Energy Efficiency and Renewable Energy of the Department of Energy under contract number DE-AC03-76SF0098 with the Lawrence Berkeley National Laboratory. 



\section{EXECUTIVE SUMMARY}

During the period 1973 to 1985 , the U.S. economy saved energy in virtually every sector. Much of this period of energy saving was also marked by a significant drop in the ratio of energy use to GDP. However, since 1985 there has been a slowdown in the rate of energy saving, as key energy intensities (space heating, automobile driving, etc) have declined less rapidly since 1985 than before.

This paper examines delivered (or final) energy consumption trends from the early 1970s to 1994 and provides a framework for measuring key changes that affect U.S. energy use. Starting with estimates of outputs or activity levels for thirty major energy end uses, and energy intensities of each end use, we use the Adaptive Weighted Divisia decomposition to measure the impact of changes in the structure of the U.S. economy. In contrast to many similar decomposition studies, we define measures of structural changes for both households and branches of transportation.

We find that between 1973 and 1985, lower energy intensities (corrected to average winter heating demand) reduced U.S. energy uses by about $1.7 \%$ per year, while structural changes reduced energy uses by $0.4 \%$ per year. After 1985 , when oil prices declined markedly, intensities fell by only $0.8 \%$ per year and structural changes actually increased energy use by $0.4 \%$ per year. In the 1990 s energy intensities in some industries have even edged upward.

Changes in the ratio of energy to GDP (E/GDP) are affected both by intensities and the changes in the demand for energy services relative to GDP. During the first period, from 1973 to 1985, GDP increased faster than the growth in key structural and activity parameters that determine demand for energy services (such as home area, appliance ownership, and motor vehicle use) by $1.5 \%$ per year. From 1985 to 1994 the difference dropped to less than $0.3 \%$ per year, largely due to the reversal of structural trends. Thus, the sharp fall in the rate of decline in E/GDP from $-3.1 \%$ to $-1.1 \%$ per year was due almost as much to structural changes as it was to the slowdown in energy intensity reduction.

The analysis presented here shows why the E/GDP is an increasingly unreliable yardstick for making measurements of how the energy-economy relationship is changing: effects not related to energy efficiency per se may have roughly the same impact on that ratio as energy saving itself. Since these effects have different causes, and potentially different impacts over the long run, looking at them in the aggregate by considering only the ratio of energy use to GDP is misleading. 


\section{Table of Contents}

EXECUTIVE SUMMARY _ _ I

INTRODUCTION __ 1

OVERVIEW OF ALL SECTORS __ 4

DECOMPOSITION METHODOLOGY _ 8

SECTORAL TRENDS IN DELIVERED ENERGY CONSUMPTION __ 11

Manufacturing _ 11

Non-manufacturing "Other" Industries___ 16

Services _ 18

Residential__ 22

Travel (Passenger Transportation)___ 28

Freight __ 32

ALL-SECTOR RESULTS _ 36

Acknowledgements __ 42

Disclaimer __ 42

APPENDIX. COMPARISON TO THE 1995 ENERGY CONSERVATION TRENDS REPORT (DOE/PO-0034)__ 43

Figures

Figure 1. United States GDP, 1970 - 1994 (real 1990 dollars) __ 3

Figure 2. Delivered Energy Consumption by Fuel

Figure 3. U.S. Delivered Energy Use per GDP by Sector, 1970 - 1994, Delivered Energy Shares, and Total Primary Intensity 5

Figure 4. Manufacturing Energy Use by Fuel with Electricity Distribution Losses 12

Figure 5. Manufacturing Delivered Energy Use per Capita, by Industry Branch 13

Figure 6. Shares of Manufacturing Value Added by Industry 14

Figure 7. Manufacturing Energy Intensities and Fuel Shares, Total and by Branch 15

Figure 8. Changes in Manufacturing Energy Use: Actual, and Decomposition Effects 15

Figure 9. Other Industries Energy Use by Fuel, with Electricity Losses 17

Figure 10. Changes in Other Industries Energy Use: Actual, and Decomposition Effects 18

Figure 11. Services Energy Use by Fuel, with Electricity Distribution Losses 19

Figure 12. Service Sector Intensities 20

Figure 13. Changes in Services Building Energy Use: Actual, and Decomposition Effects 21 
Figure 14. Residential Energy by Fuel (Climate Corrected), with Electricity Transformation and Distribution Losses

Figure 15. Residential Delivered Energy Use per Capita by End-Use

Figure 16. Personal Consumption Expenditures vs. Dwelling Area per Capita, 1970-1997 25

Figure 17. Changes in Residential Energy Use: Actual and Decomposition Effects 27

Figure 18. Travel Delivered Energy Use, Total and per Capita by Mode 29

Figure 19. Travel Activity by Mode, with 1970 and 1994 Shares 29

Figure 20. Modal Energy Intensity (Energy per PKM) by Travel Mode, with Auto Vehicle Intensity 30

Figure 21. Travel Load Factors by Mode 31

Figure 22. Changes in Travel Energy Use: Actual and Decomposition Effects 31

Figure 23. Freight Energy Use per Capita by Mode 33

Figure 24. Freight Activity by Mode, with 1970 and 1994 Shares 33

Figure 25. Freight Modal Intensities 34

Figure 26. Changes in Freight Energy Use: Actual and Decomposition Effects 35

Figure 27. All-Sector Sum of Decomposition Results 36

Figure 28. Changes in Key Intensities, Indexed to 1990 38

Figure 29. Savings in Primary Energy Use in the U.S. Economy 1973-1994. Sector by Sector and Total. 39

Figure 30. Average Annual Rates of Growth of All-Sector Decomposition Terms, 73-85 vs. 8594

\section{Tables}

Table 1. Measures of Activity, Sectoral Structure and Energy Intensities 10

Table 2. Other Industries Value Added and Delivered Energy Intensities 17

Table 3. Change in Terms Affecting Residential Enery Use 24

Table 4. Unit Energy Consumption and Saturations of Major Appliances 26

Table 5. Difference in Delivered Energy Consumption (PJ) in 1994 vs. 1970 by Decomposition Term $^{1}$ 


\section{INTRODUCTION}

During the period 1973 to 1985 , the U.S. economy saved energy in every sector. Much of this period of energy saving was also marked by a significant drop in the ratio of energy use to GDP (E/GDP). Since that time, however there is has been a slowdown in the rate of energy saving, as key energy intensities (space heating, automobile driving, etc) have declined less rapidly (or in some cases begun to increase) since 1990 than before. Is the U.S. economy still saving energy at its previous rate? This paper examines the energy saving through the early 1970s to 1994 to provide a framework for measuring key changes that affect U.S. energy use, including energy saving. We examine some of the disaggregated trends in energy use after 1994 and show that the drop in the E/GDP ratio is primarily explained by structural trends: motor vehicle use, air travel, home area and appliance ownership grew in the late 1990s, but not nearly as rapidly as GDP grew. ${ }^{1}$ Additionally, light industry (particularly information technologies) led the growth in output in the manufacturing sector. This means that energy saving may not be the principal reason for the drop in the ratio of energy use to GDP after 1994. Therefore, the potential for energy saving may be higher than thought, if changes in the ratio of energy use to GDP are used to measure that potential. In all of this work, however, we show that the ratio of energy use to GDP is an increasingly unreliable yardstick for making this measurement, because effects not related to energy saving per se may have roughly the same impact on that ratio as energy saving itself.

\section{Background: Changes in Energy Use in the U.S. Economy over Time}

To measure how the U.S. economy as a whole is changing, we use index decomposition techniques. These take changes in energy use in each sector and decompose them into changes caused by evolution in the overall activity level in that sector, changes in the structure or mix of activity or output in that sector, and changes in individual energy intensities in that sector. To the extent we can ignore the small interaction by which lower-than-otherwise energy intensities stimulate activities for which energy is used, i.e. the rebound effect, we can measure how much less energy the U.S. economy is using because of lower energy intensities. On the other hand, where structural changes lead to reductions in energy use, these will be identified as such.

Making this decomposition is important for several reasons. The most important is to isolate the energy intensity components of changes in energy use. Other factors that tend to affect energy use, such as higher output from the productive economy, greater consumer expenditures, greater population, and more subtle factors such as changes in household size and composition of manufacturing industries, are largely independent of energy intensities. The changes in energy use due to these forces should not be conflated with energy savings in measuring the productivity of energy use in the economy. A decomposition based on disaggregated data quantifies the effects of structural changes and activity growth distinct from the effects of changes due to energy intensities.

A second reason is that more accurate measures of changes in energy intensities are necessary in order to gauge the impacts of the stimuli for saving energy on energy consumption. There is no doubt, for example, that individual consumers reduced heating needs in their homes in response to increased energy prices in the 1970s. Our approach permits estimating how large that reduction has been, relative to the size of homes. One could compare that reduction with what might be accounted for by increased insulation and other measures to the building shell; improved heating equipment; the entrance of new, better insulated homes into the housing stock; the retirement of older, leaky homes; changes in indoor temperatures; and so on. However, that level of detail is beyond the scope of this

\footnotetext{
${ }^{1}$ A forthcoming report will examine decomposition trends through 1998.
} 
brief project, but such detail has been analyzed in previous work undertaken by the Pacific Northwest National Laboratory.

Additionally, decompositions of past trends may help modelers more accurately project future changes in energy use. Structural and intensity trends can be thus be modeled separately and their effects combined to more accurately estimate future demand for energy.

\section{Measuring Saved Energy}

The fundamental problem that motivates this research is that the most widespread indicator of energy use and energy efficiency - the E/GDP ratio - is a very crude indicator. Little can be said, on the basis of that ratio, about why energy use for any sector has reached a certain level, how efficient that use is, or why levels for otherwise similar countries differ so much. Better tools are required, tools that this work will apply to U.S. energy use.

The difficulty with using E/GDP as a tool is that the denominator - GDP - represents many diverse activities that vary among countries and change over time. Since the energy intensities of these activities differ widely from each other, differences or variations in the mix of activities can cause significant variations in this ratio over time without any intensities changing. Considerable efforts by federal and state authorities have promoted greater energy efficiency for many end uses. Since efficiencies are a function of specific physical processes or of specific economic activities, it is hard to take seriously an aggregate ratio of all energy uses to GDP as an indicator of energy efficiencies. No amount of manipulation of that quantity alone can ferret out the contribution of energy efficiency, much less the parts related to higher prices, government programmes, or technological progress. In response to these weaknesses, disaggregated indicators of energy uses and activities match numerators and denominators as closely as possible.

This work will therefore move beyond the E/GDP ratio by using decomposition to show the role of intensity changes in each sector. Then the results from each sector will be assembled into an economy-wide measure of the importance of each component of energy use. Where significant, key structural changes will also be highlighted by sector and for the economy as a whole. This approach permits analysts to judge the relative importance of these structural changes vis-à-vis the intensity changes.

Broadly, energy intensities are the ratios of energy use to specific activities or outputs. These indicators measure the energy used per unit of energy service delivered - for example, per dollar's worth of value added or per square meter of household heated. They may embody both improvements in physical efficiencies, narrowly-defined, as well as changes in other characteristics of energy use (e.g. changes in manufacturing process, indoor temperature and heating hours, new car size and power, or refrigerator size). Unfortunately, measuring energy efficiencies for the entire economy at lower levels of disaggregation than performed here is not feasible, given currently available information.

Once energy intensity changes have been identified, the total savings in energy in any given year is the change in each intensity (from a base year) times the activity level for each energy use in the given year. Thus, if cars, private light trucks, and SUVs used 6 liters/100 km less fuel in 1994 than they did in 1973 (or approximately $1.8 \mathrm{MJ} /$ vehicle-km, corresponding to a change in fleet fuel 
economy of approximately $13 \mathrm{MPG}$ to $20 \mathrm{MPG}$ ), and there were 3.2 trillion vehicle-km driven, then the total savings was 6,300 petajoules $(\mathrm{PJ})$ of fuel. ${ }^{2}$

\section{The Aggregate View.}

This study examines energy use in the U.S. from 1970 to 1994, the last year for which official data were available for all energy-using sectors at the time of this study. The analysis has been extended further for sectors having more recent data. Several trends have affected energy use in the U.S. over this time period. One important driver has been growth in the U.S. economy. Between 1970 and 1994 the real value of U.S. economic output nearly doubled. Figure 1 shows that the GDP increased from about three trillion to six trillion constant 1990 dollars. Growth among the sectors was relatively even, although services value added share increased from $65 \%$ to $71 \%$, while the shares of mining and construction decreased.

\section{Figure 1. United States GDP, 1970 - 1994 (real 1990 dollars)}

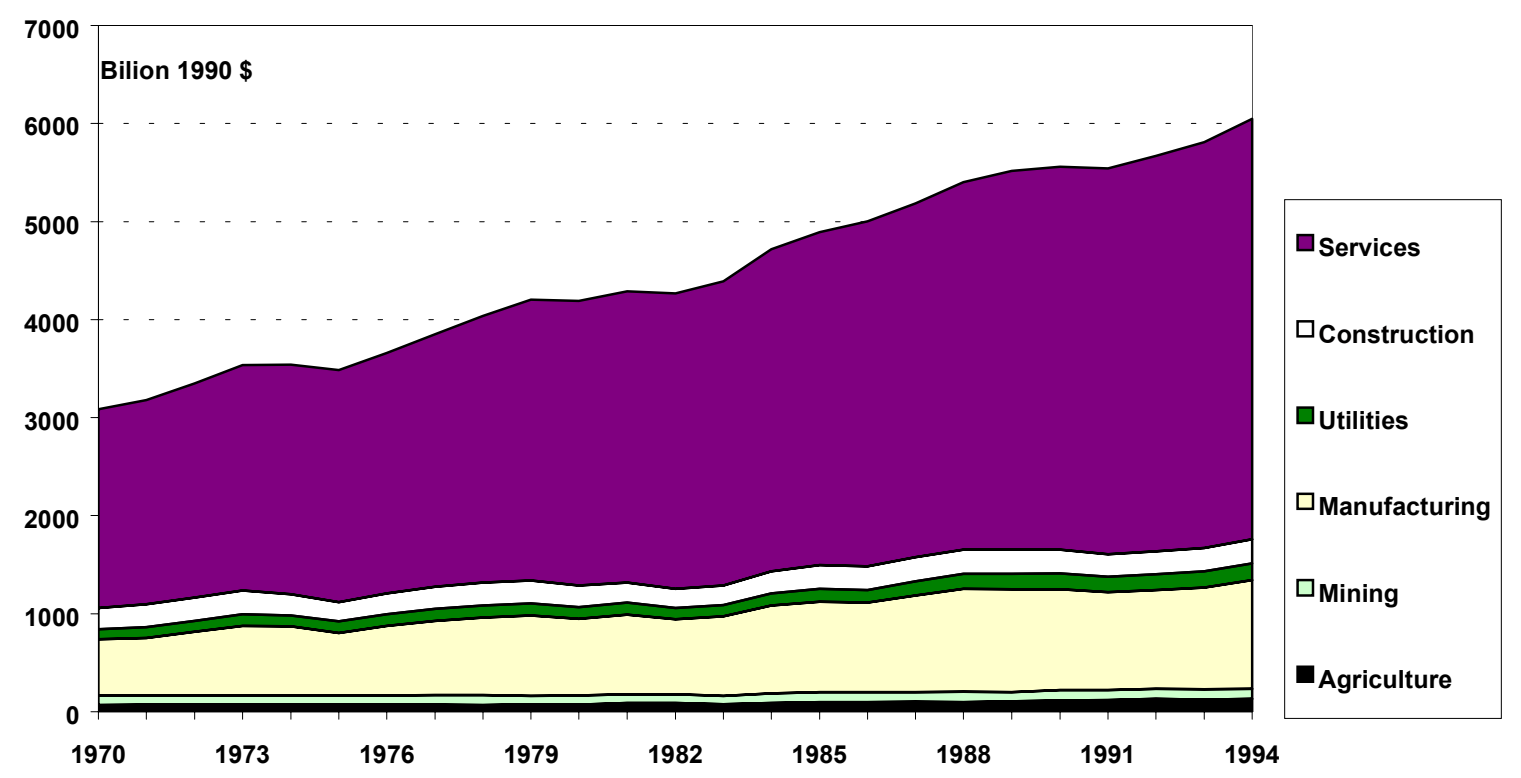

If the E/GDP ratio were to remain constant, a real doubling of GDP would imply a doubling of energy consumption. However, total annual delivered energy use, as measured bottom-up in this study, rose only about $20 \%$, from 45 thousand to 55 thousand PJ. Thus, approximately 35 thousand PJ were "saved" in 1994 compared to the hypothetical energy use at a constant E/GDP ratio. However, as we show below, changes in the demand for energy services relative to GDP were responsible for more than a third of this.

\footnotetext{
2 This calculation ignores the small rebound effect between changes in intensity and changes in activity level, i.e., if for some reason fuel economy had been frozen at its 1973 level in 1994, the number of km driven would have been slightly lower because the fuel cost of each km would have been higher. See the June/July 2000 Special Issue of Energy Policy.
} 


\section{OVERVIEW OF ALL SECTORS}

The overview begins with a review of the progress of fuel mix over time, as shown in Figure 2. Consumption of solids, including coal and coke, steadily diminished relative to other fuels, as gas and electricity provided greater shares of space and water heating in buildings and as activity in the coalintensive industries (iron/steel, cement) failed to keep pace with overall economic growth. Renewables (such as wastes in the paper industry) hit their maximum share in the early 1980s when wood was popular for space heating. The share of oil was propelled upward by increased transport activity, but reduced by massive substitution towards natural gas in industry, homes, and buildings. Natural gas itself gained market share as a principal fuel in all of those sectors, but its use was reduced through greater efficiency, particularly for space heating. Electricity gained share primarily as electricity uses proliferated (lighting, computing and information, appliances, and motors in buildings). Electricity also captured a larger share of space and water heating in new homes and buildings. But like natural gas, electricity uses were reduced through greater efficiency.

\section{Figure 2. Delivered Energy Consumption by Fuel}

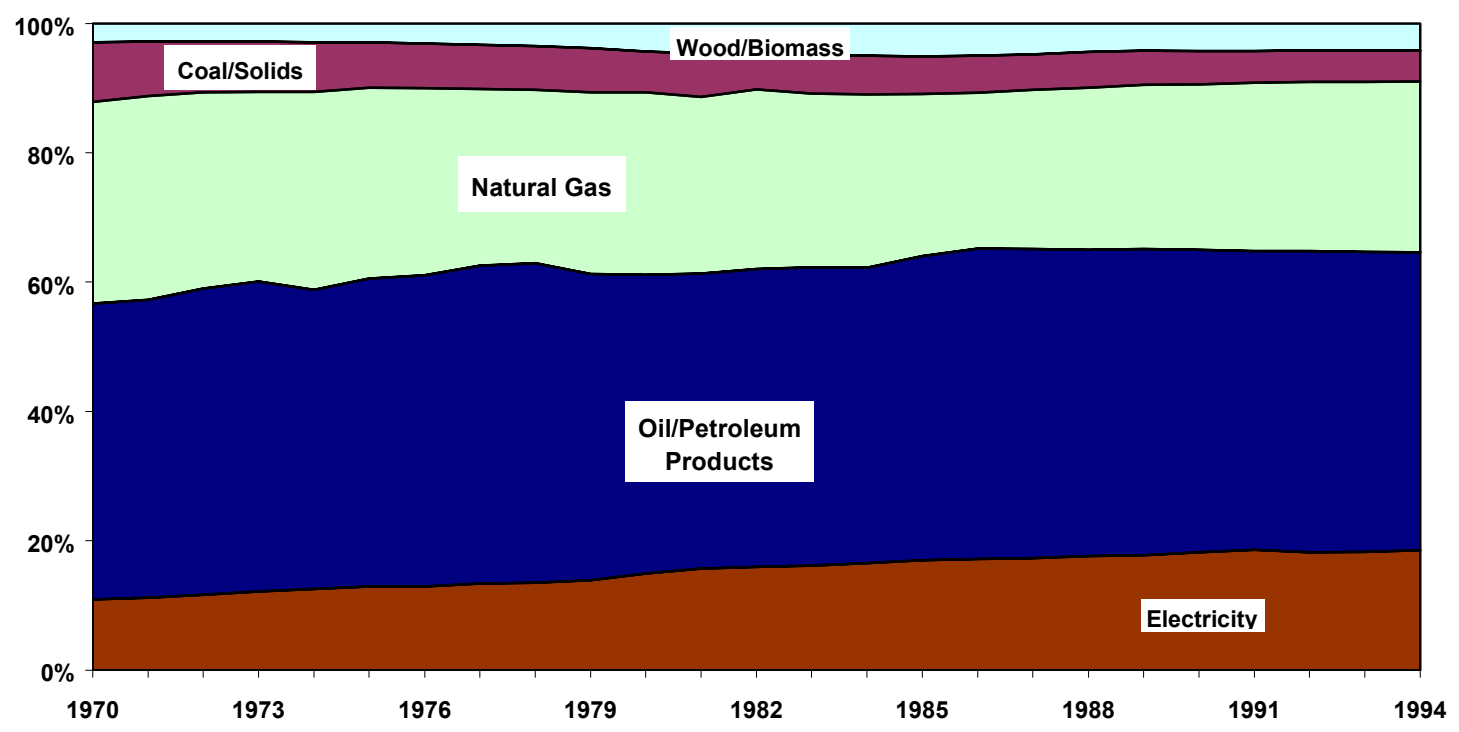

The increasing share of electricity has an important impact on the interpretation of changes in delivered energy in residential and service buildings. On the one hand, this meant less delivered energy lost from combustion for heating and cooking, which would appear as a decline in delivered energy intensities for some end uses. On the other, the increased share of electricity in these sectors (and manufacturing) meant greater overall primary energy losses from generating and distributing electricity. Consequently, in some contexts we discuss the changes in delivered and primary energy intensities (as well as "useful" energy intensities in the residential sector), since the results can differ substantially.

The fuels and electricity used in this study are derived bottom-up from studies of each sector. The sectoral Energy Consumption Surveys produced by the Department of Energy are the principal surveys used for the period from the late 1970s. Fuel uses in transportation are taken from the Oak Ridge Transportation/Energy Data book, and data for the non-manufacturing industries are from the National Energy Accounts (to 1985) and from the Energy Information Administration's (EIA) Annual Energy Outlook estimates (from the early 1990s). We use top-down totals from the State Energy Data Reports $^{\text {ii }}$ (SEDR) for energy consumption by commercial buildings. Floor area estimates are from a data series supplied by Pacific Northwest National Lab, which is based on the Commercial Buildings 
Energy Consumption Surveys and additional data from F.W. Dodge. Since the entire study is built up mostly from sectoral data, the totals may disagree somewhat with the national totals provided by SEDR, which include a significant amount of fuel used in transportation and in various branches of industry not accounted for in this study. In general, the present accounting reaches to $80 \%$ of the delivered energy consumption in SEDR. The overwhelming share of the difference is oil losses in refining, oil used in miscellaneous transportation and the military, natural gas consumed in pipelines, electricity consumed in pipelines and water pumping, asphalt and road oils, and chemical feed-stocks. One reason for omitting the refining industry is the unreliability of using value added for measuring output, a quantity that fluctuates significantly with changes in world prices. Another problem is the uncertainties in data from before 1975. Excluding industry, where the refining and feedstock differences arise, the truly unaccounted for energy use is about $5 \%$ of the total primary energy use consumed in any year.

Figure 3 shows how this final energy was distributed over six main sectors. Manufacturing and other industry lost considerable share in the total, while freight increased. Figure 3 reveals the sharp decline that has occurred since 1970. By 1994 the U.S. economy was consuming about 8.7 megajoules (MJ)/1990\$, a reduction of nearly 40\% from the 1970 level. (Primary energy intensity also declined, but only by $28 \%$.) However, as is clear from the figure, most of this decline occurred over the period from 1977 to 1985. Between 1985 and 1994 this economy-wide indicator of delivered energy intensity fell by only another $7 \%$. The majority - but not all - of this decline is related to energy saving.

The last two bars in Figure 3 show how total final energy use was allocated among key subsectors in both 1970 and 1994. These bars reveal that relative shares of energy use have changed considerably for certain sectors. Most importantly, the shares of energy consumed by residential space heat and manufacturing have declined while services' electricity, travel, and trucking have gained share.

Figure 3. U.S. Delivered Energy Use per GDP by Sector, 1970 - 1994, Delivered Energy Shares, and Total Primary Intensity

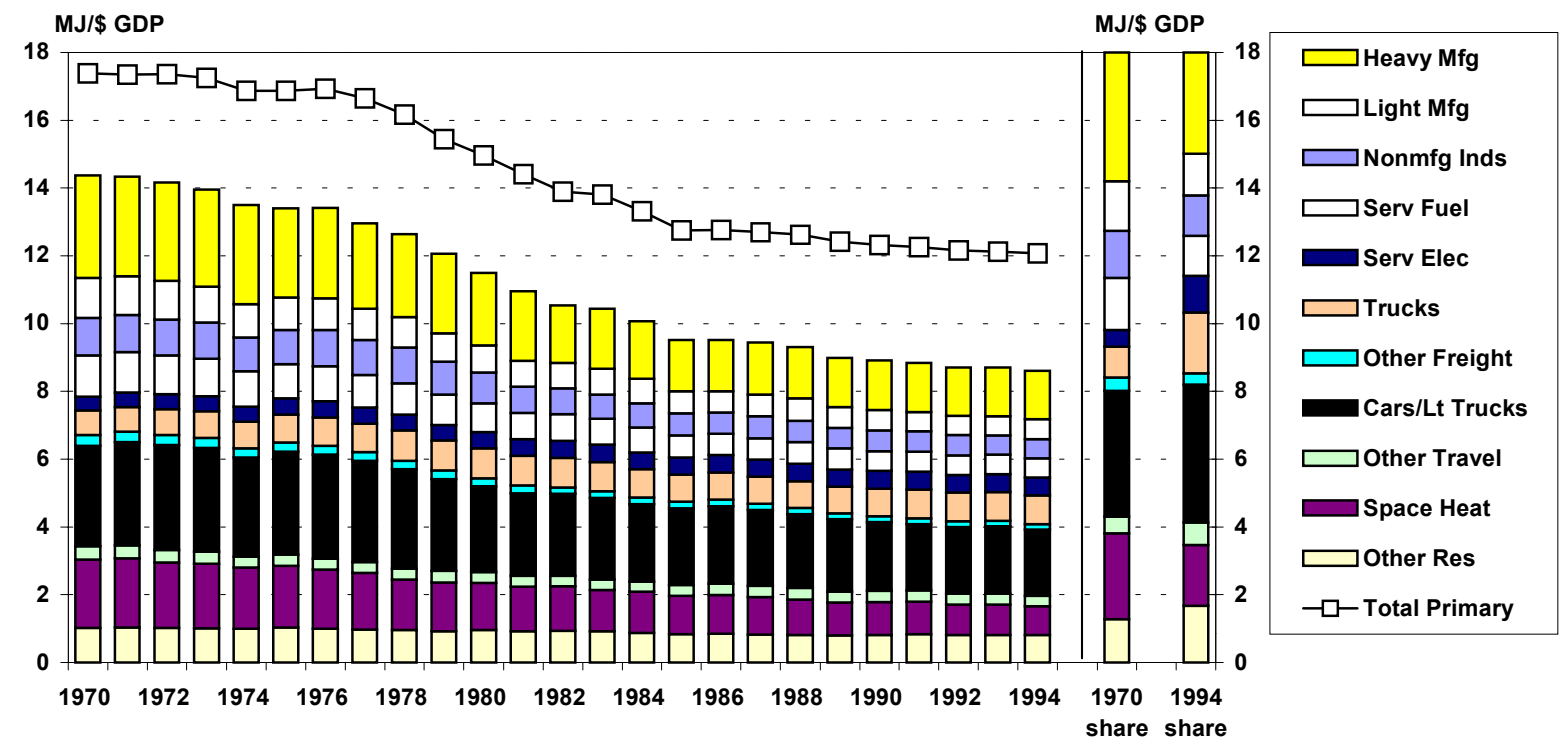

To what extent has the energy saved since 1970 resulted from real declines in the amount of energy used to provide a given level of energy services? In order to better isolate the role of energy intensity, we apply the Adaptive Weighted Divisia index to decompose these trends and attribute the changes in energy consumption to the underlying activity, structure, and intensity factors. For this study we 
disaggregate total energy use into thirty-one separate end-uses across six energy-using sectors: manufacturing industries, non-manufacturing industries, freight, travel, residential, and services. The decomposition of the trends in delivered energy use for each of these sectors illustrates the relative importance of energy intensity and structural changes, both by sector and to the economy as a whole.

The approach employed in this report is sketched below.

- Disaggregation of E/GDP into the components of E: Activity, Structure, and Intensity.

- Disaggregation of each sector's energy use into subsectors (branches of manufacturing), modes (passenger and freight transport), or end-uses (households).

- Identification of measures of output or activity for each of the subsectors of energy use.

- Analysis of trends in energy uses, energy intensities, and structural measures.

- Brief comparison of trends with changes in measures of income and in energy prices.

- Re-aggregation of results into economy-wide components and interpretation of the all-sector time trends.

- Discussion of the increasing share of electricity in delivered energy and the implications for total primary energy consumption.

Figure 3 also demonstrates that the shares of total energy use among the six sectors have changed over time. Freight's share experienced the greatest relative change, increasing from $6.8 \%$ to $10.7 \%$ of total energy use. Travel and services also increased while manufacturing, other industries, and residential sectors all decreased by about the same amount. Subsequent sections will provide greater detail about the evolution of energy use in each of these sectors. 


\section{Box 1. Definition of Key Terms}

Delivered energy or final consumption:

Energy supplies delivered, for example, to a building, factory or fuel tank and converted ultimately to heat, light, motion or other energy service. Transformation and distribution losses related to purchases of electricity and district heat are not included. Energy consumption is measured in joules of lower heating value (i.e. net calorific value).

\section{Primary energy:}

Delivered energy plus losses incurred in converting energy resources into purchased heat and electricity.

\section{Useful Energy:}

Delivered energy minus losses assumed to occur in boilers, furnaces, water heaters and other equipment in buildings; used for estimates of heat provided in space and water heating and cooking.

\section{Activity or output:}

Basic unit of accounting for which energy is used, e.g. in the residential sector it is population; in manufacturing, it is value added. Activity also connotes an aggregate measure of sectoral output.

\section{Structure or subsectoral activity:}

Refers to the shares of sectoral activity accounted for by each subsector. In the residential sector, it is a measure of space heated/lit or appliances owned per capita. This is necessary as there is no "common currency" to compare the energy services provided by the various residential end-uses. In the services sector, due to data limitations, we define structure as average ratio of floor area to value added for the sector.

\section{Energy services:}

Implies actual services for which energy is used: heating a given amount of space to a standard temperature for a period of time, etc. In practice, energy services combine activity and structure. The combination of these two terms tracks the changes in energy use due to the total demand for services provided by energy.

\section{Energy intensity:}

Energy "consumed" per unit of activity or output for each major end-use or energy-using subsector. Energy intensities are determined at the subsectoral level to control as much as possible for structural changes. Energy intensities are related to the inverse of energy efficiencies through the quality or attributes of energy use, such as the temperature of a heated room, weight and power of a driven car, quality of steel produced, or size and inside temperature of a refrigerator. Since the latter quantities are very hard to determine for the entire economy year after year, the focus must be on energy intensities, with an eye to indirect measures or indicators of efficiencies.

Note: U.S. fuel data are usually reported in Higher Heating or Gross Calorific Value (GCV), by which the energy lost to moisture evaporation in the fuel is counted as consumed energy. For consistency with international practices, all energy values in this report are converted to net calorific values (NCV), which subtracts this energy of vaporization. This means a reduction in the GCV energy content of natural gas by $10 \%$, oil products by approximately $5 \%$, and coal by about $7 \%$. Furthermore, data are presented in Standard International Units. The main unit of U.S. energy use, the Quad (or quadrillion BTU or 1000 Trillion BTU) is 1.055 exajoules (EJ) or 1055 Petajoules (PJ). Because of the conversion to net heating value, a figure quoted in EJ or PJ in NCV in this report is very close to its corresponding value in BTU measured in GCV. The same is true for intensities quoted in megajoules per unit of activity, which work out very close to thousand BTU per unit of activity. 


\section{DECOMPOSITION METHODOLOGY}

In order to further understand what underlying factors have been principally responsible for the changes in energy use, we decompose the changes in each sector's energy use into three decomposition factors: activity, structure, and intensity. Changes in energy use are attributed to the underlying decomposition factors to determine the direction and magnitude that these effects have had over time. In this section we describe in general terms our decomposition approach while a more detailed presentation of the methodology can be found in Greening et al. 1997 (see endnote iv).

Depending on the sector, activity is measured either as value added in GDP (manufacturing, services, other industry), passenger-kilometers ( $\mathrm{pkm}$ ), metric ton-kilometers (tkm), or population. Generally, structure is defined as the composition of subsectoral shares of sectoral activity. In the manufacturing sector, for example, structure is defined as the relative shares of each industry branch in total manufacturing value added (see Box 1). More detailed description of these measures are given for each sector in subsequent sections.

Combining activity and structure yields what we refer to as energy services, i.e. the total change in the demand for energy at fixed intensities. This is important because increased energy services raises energy use but not in ways that mean "unsaving" of energy. For example, the number of air conditioners and dryers has grown, relative to the number of households. All else equal, this change, permitted by higher incomes and lower prices for these appliances raised household electricity use significantly. But that increase is not counted "against" energy savings. On the other hand, if these appliances are larger and consume more energy because of their size, our approach would count the increase in energy use per appliance against energy savings. The same is true for automobile size and power or indoor temperatures. The reason is that these variables do tend to contract or grow more slowly in times of high energy prices, more so than the number themselves of appliances, cars, or homes. Thus by separating to the best extent possible the "structural" features of energy use that are relatively independent from concerns about energy savings, we are left with an energy intensity that is directly related to saving.

This "energy services" term may also be thought of as a kind of hybrid physical/monetary GDP. While parts of it are made up of GDP components, the transport and household components are physical in nature and not readily measured in the national accounts. Each of the sectoral indices can be visualized as the amount by which energy use in that sector is changed by a combination of changes in either physical or monetary activity or output levels. By comparing changes in the index values of this energy services term for the entire economy with changes in GDP, we can identify important shifts in the nature of the economy that either increase or decrease the ratio of energy use to GDP that are largely independent of changes in individual energy efficiencies or energy intensities. Over the long term, such changes, whether caused by saturation of some activities (driving, production of energy-intensive materials, home area heated) or by rapid growth in activities that are not energy intensive (such as activities whose main content is information or services with little or no transport or area in buildings required) could have profound impacts on the coupling between energy use and GDP. In identifying such changes that took place up to 1994, we can show which part of the overall decline in the U.S. E/GDP ratio are attributable to energy-efficiency policies, the emergence of energy-efficiency technologies, or changes in consumer energy-using behavior.

\section{Decomposition in A Simple Mathematical Framework}

The algebra of decomposition can be written down in a relatively straightforward way that has come to be known as "ASI". We decompose energy use $\mathbf{E}$ as follows: 


$$
\mathbf{E}=\sum \mathbf{A}_{\mathbf{i}} * \mathbf{S}_{\mathrm{i}, \mathrm{j}} * \mathbf{I}_{\mathbf{i}, \mathbf{j}}
$$

A represents overall sectoral activity in each $i$ sector, say GDP in manufacturing, $\mathbf{S}$ represents sectoral structure expressed as share of output or activity or levels of household equipment ownership. I represents the energy intensity of each branch $\boldsymbol{i}$ shown in $\mathbf{S}$ (in energy use/real money output). The summation is then taken over $\boldsymbol{i}$ and $\boldsymbol{j}$. The present effort disaggregates $\mathbf{A}, \mathbf{S}$, and $\mathbf{I}$ into subsectoral components because this disaggregation reveals important new information about how energy use has changed.

Now divide both sides of Eq. (1) by GDP, denoting GDP by $\mathbf{Y}$ and $\mathbf{E} / \mathbf{Y}$ by $\mathbf{R}$

$$
\mathbf{R}=\left[\Sigma\left(\mathbf{A}_{\mathbf{j}} * \mathbf{S}_{\mathrm{i}, \mathrm{j}} * \mathbf{I}_{\mathrm{i}, \mathrm{j}}\right)\right] / \mathbf{Y}=\left[\Sigma\left(\left(\mathbf{A}_{\mathbf{j}} * \mathbf{S}_{\mathrm{i}, \mathrm{j}} / \mathbf{Y}\right) * \mathbf{I}_{\mathbf{I}}\right)\right]
$$

We have purposely moved $\mathbf{Y}$ (a scalar) into the summation to emphasize that the left-hand side can change either because the I changes or because AS/Y changes. As noted in the introduction, if activity levels associated with certain large uses of energy, such as steel produced, km driven, area heated, or tonne-km hauled, simply fail to grow as rapidly as GDP, $\mathbf{R}$ will decline even though "energy saving" as defined here has not changed. Such was the effect of these structural changes in Japan between 1970 and the early 1990s, accounting for nearly $50 \%$ of the overall decline in $\mathbf{R}$ ! viii Conversely, the aforementioned indicators might rise more rapidly than $\mathbf{Y}$, causing $\mathbf{R}$ to increase, even though individual I fell, a situation observed in New Zealand between 1980 and 1994 or briefly in the U.S. in the late 1960s. Or, enough of the changes in the $\mathbf{A}_{\mathbf{j}} * \mathbf{S}_{\mathbf{I}, \mathbf{j}}$ could be towards higher energy use to offset significantly other changes that were reducing $\mathrm{R}$, which was observed in the Netherlands and Finland in the period 1973-1994. These international examples make it clear that the change in the ratio of energy to GDP often gives a very misleading picture of how energy use is changing.

Index number techniques permit analysing how this relationship changes over time. The simplest indices are Laspeyres or Paasche indices applied to discrete data, usually over time. The former approach holds all but one of the members of the right-hand side of Eq. 1 constant in a starting base year to study the impact of the third member changing, while the latter hold quantities constant in final year values. A problem with either of these forms is the presence of residual quantities that arise. Divisia indices present a more complicated form using logarithms of differences, with less residual problem, while Adaptive weighted Divisia have almost no residuals. Whatever the method, indexing provides a powerful approach to understanding how multiplicative factors of energy use affect the total.

Indexing has been applied to transportation, ${ }^{\mathrm{iii}}$ manufacturing, ${ }^{\mathrm{iv}}$ non-manufacturing industries, ${ }^{\mathrm{v}}$ and households. ${ }^{\text {vi }}$ With suitable assumptions, individual sector results can then be combined to given economy-wide measures of changes in energy use with Laspeyres indices ${ }^{\text {vii }}$ or with AWD Indices. ${ }^{\text {vii }}$ An extension of this methodology, the "Mine/Yours" comparison, allows comparison of two countries or one country against a number of others. In this approach, $\mathbf{A}, \mathbf{S}$, or I of one country (or an average of other countries) is substituted for $\mathbf{A}, \mathbf{S}$, or $\mathbf{I}$ of a country under study and the resulting $\mathbf{E}$ compared with actual $\mathbf{E}$. The result shows how important a single component is the difference in emissions between any country and any other(s). ${ }^{\text {ix }}$

Table 1 provides a list of the sectors, end-uses, and subsectors studied in this report. It should be noted that data for "other industry" are very difficult to find, hence little effort was spent on this sector. 
Table 1. Measures of Activity, Sectoral Structure and Energy Intensities

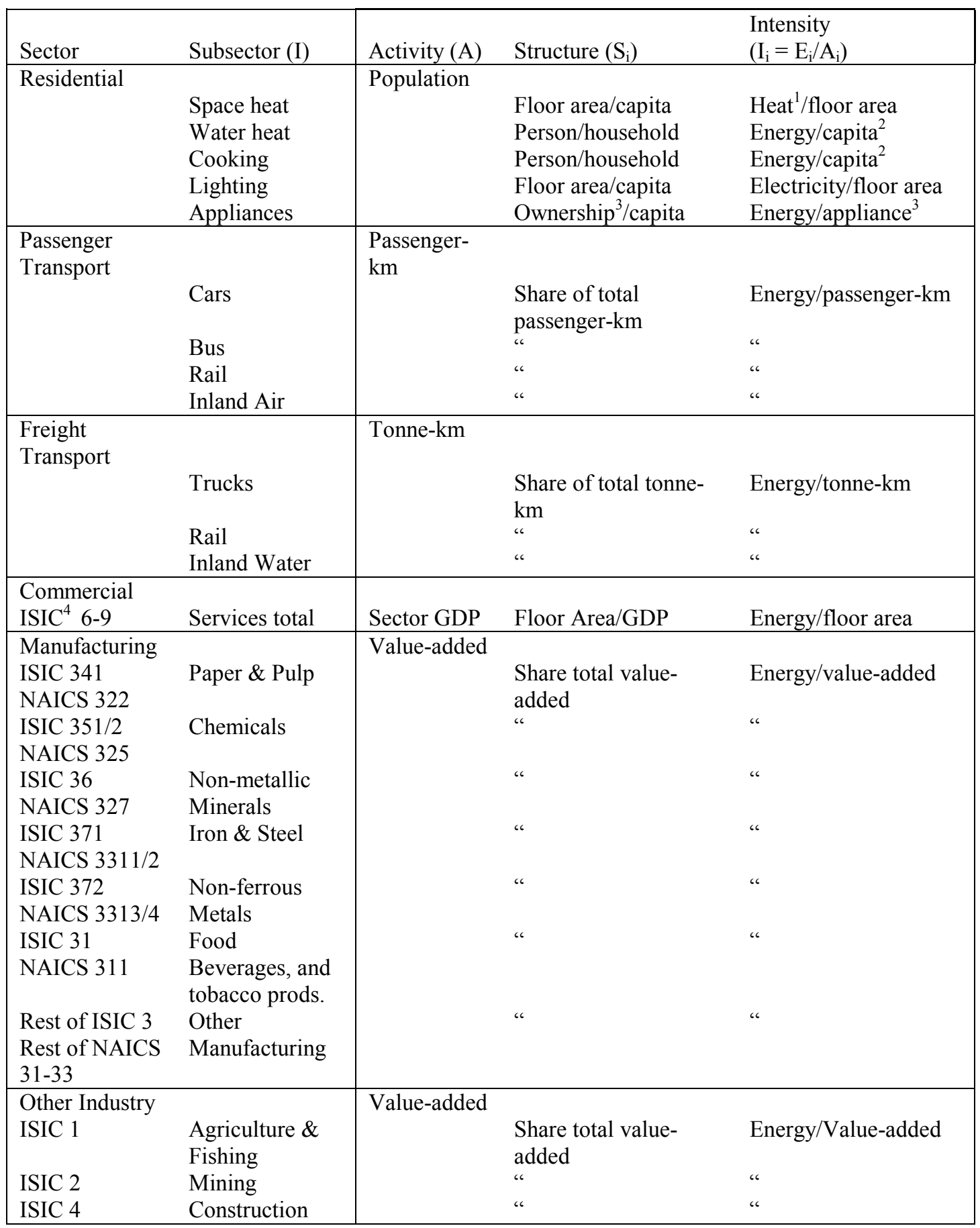

Source: Schipper L, F Unander, et al. 2000. Energy Use in Australia in an International Perspective: Comparison of Trends Through the Mid 1990s. Paris: Int'l Energy Agency

1. Adjusted for climate variations and for changes in the share of homes with central-heating systems.

2. Adjusted for home occupancy (number of persons per household).

3. Includes ownership and electricity use for six major appliances.

4. International Standard Industrial Classification Sector.

Note that the measures of activity contain both physical and monetary measures. 


\section{SECTORAL TRENDS IN DELIVERED ENERGY CONSUMPTION}

In this section we shall review the main trends in energy use in each sector. We present key definitions, conventions, and data source information at the beginning. We also note important differences between our approach and that of previous reports.

\section{MANUFACTURING}

Box 2. Manufacturing Sector Data Sources and Methodology

End-Uses/Subsectors: Manufacturing is disaggregated into seven subsectors:

- $\quad$ Paper and pulp (NAICS 322, ISIC 341)

- $\quad$ Chemicals (NAICS 325, ISIC 351 and 352)

- $\quad$ Non-metallic minerals (NAICS 327, ISIC 36)

- $\quad$ Iron and steel (NAICS 3311 and 3312, ISIC 371)

- $\quad$ Non-ferrous metals (NAICS 3313 and 3314, ISIC 372)

- $\quad$ Food and kindred products (NAICS 311, ISIC 31)

- $\quad$ Other manufacturing industries (all remaining subsectors of NAICS 31-33, or ISIC 3, excluding refining).

The first five subsectors refer to the production of raw materials. In order to ensure international comparability, the disaggregation is done at the 2 or 3 -digit ISIC sector level. Moving to a consistent 3 or 4-digit for the entire time period, while desirable, runs into enormous data limitations and costs. Refining is omitted because of data problems.

Activity: Contribution to GDP from manufacturing industries, here termed value-added, measured in real 1990 dollars.

Structure: Mix of manufacturing output, measured as relative shares of value-added among the subsectors. Terms are additive to total GDP in manufacturing. Source is the Gross Domestic Product Accounts .

Intensity: Delivered (final) energy use per unit of activity (value added). Energy intensity is measured in terms of economic output because of the near impossibility of accurately measuring the energy intensities of individual manufacturing products over long periods. Additionally, value added facilitates comparability across manufacturing branches and among thousands of intermediate and final products.

Data Sources: Final demand 1970-1985 is from the National Energy Accounts, Dept. of Commerce, and from 1985 to 1994 in three year intervals from the Manufacturing Energy Consumption Surveys (MECS) ${ }^{\text {xi }}$ Values of energy demand by subsector for years not covered by MECS are estimated by interpolating each intensity (by fuel, per unit of value added in the subsector) and multiplying the result by value added in that subsector for the year in question. Interpolation is linear. Manufacturing value added data are from the National Income and Product Accounts. 
Figure 4. Manufacturing Energy Use by Fuel with Electricity Distribution Losses

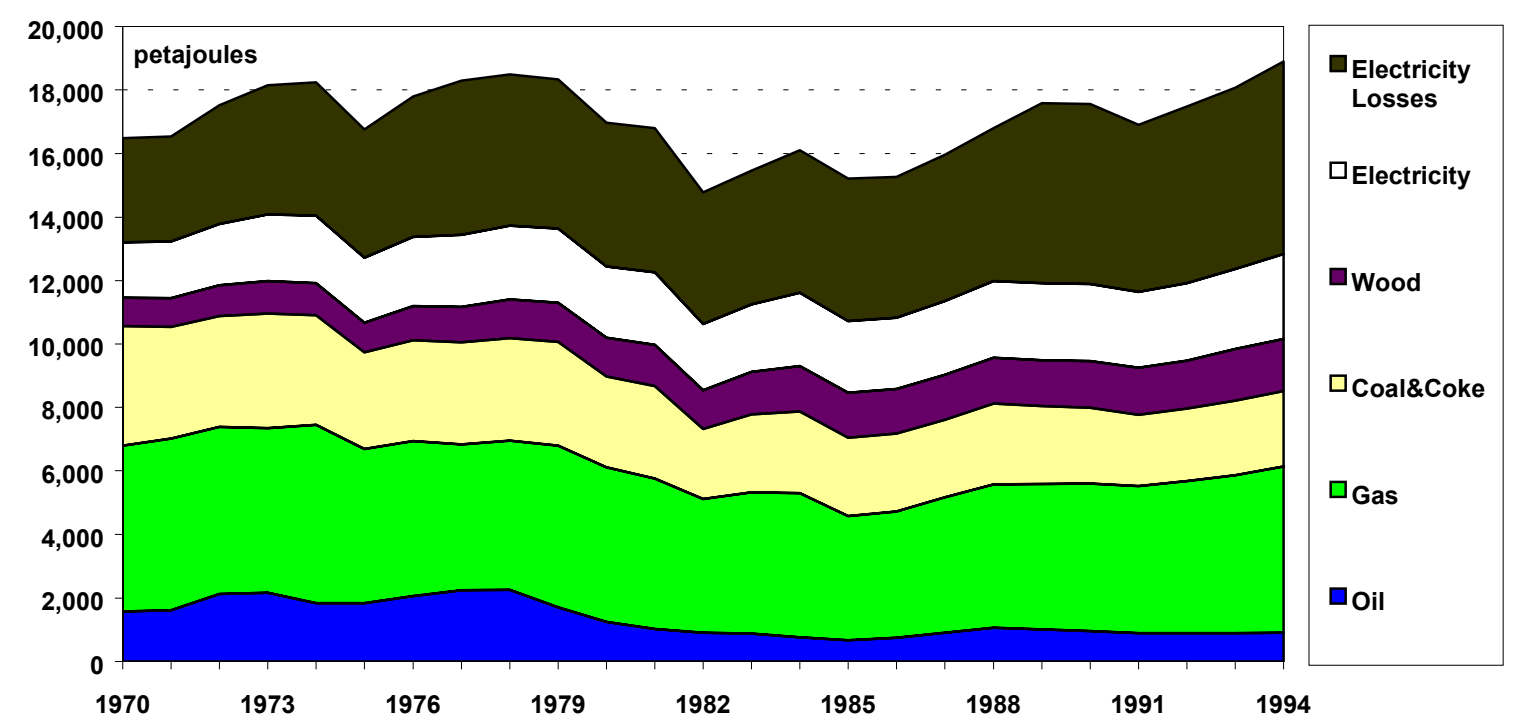

Delivered energy use by U.S. manufacturers declined rapidly between 1970 and 1985 . However, by 1994 energy consumption had returned to the levels of the early 1970s. Figure 4 depicts the changes in delivered energy use by fuel, with total primary energy given by the addition of electricity losses. ${ }^{3}$ The shares of oil products and coal fell substantially, particularly during the period of high energy prices beginning in 1979. The decreasing shares of these fossil fuels were replaced by wood and electricity, leaving the share of natural gas virtually unchanged. Wood and other biomass is used as a significant energy source only in the pulp and paper, food processing, and some industries in the miscellaneous manufacturing subsector. About two-thirds of the increase in wood use originates in the pulp and paper industry with food processing and other manufacturing contributing equally to the remainder. Every industry experienced an increase in the share of electricity, bringing the share of electricity up from $13 \%$ to $21 \%$, with the largest relative increases occurring in the nonmetallic minerals and ferrous metals industries. The trend toward greater electrification had a significant impact on total primary energy use in this sector: while delivered energy use remained virtually unchanged by the end of the study period, primary energy use increased $17 \%$.

\footnotetext{
${ }^{3}$ The calculation for 1994 excludes "other energy sources" which accounted for about 3\% of delivered energy that year.
} 
Figure 5. Manufacturing Delivered Energy Use per Capita, by Industry Branch

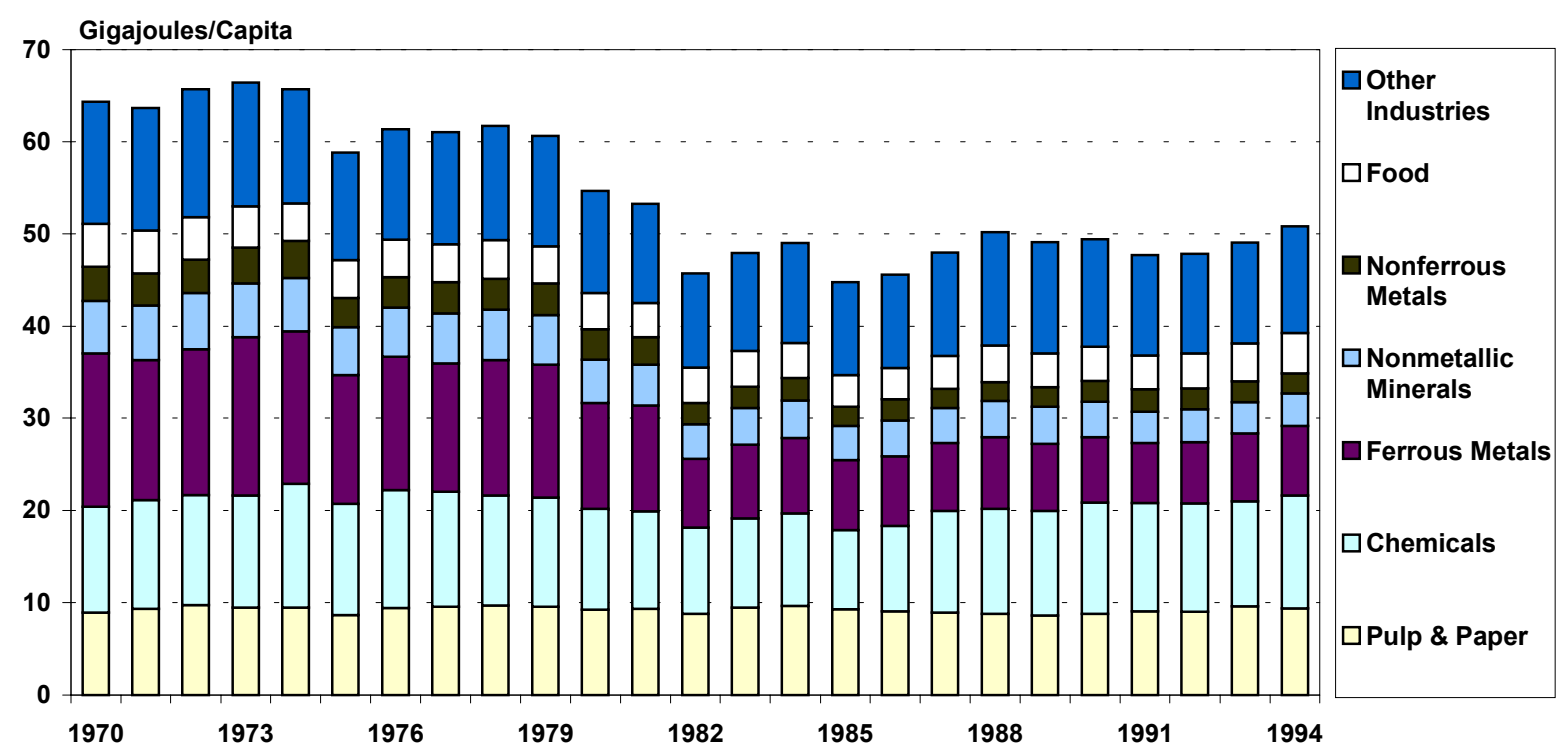

Figure 5 breaks down manufacturing delivered energy use per capita by manufacturing branch. This figure shows that in per capita terms energy use has declined, despite increasing value-added per capita. However, energy consumption per capita reached its lowest point in 1985, and has changed little since 1988, a period of relatively low energy prices.

A key factor driving up energy use has been manufacturing output. Overall, manufacturing value added increased $93 \%$ in real terms from 1970 to 1994 . However, the recessions of the early 1980s and early 1990s actually decreased demand for energy services during periods when the energy-reducing structural and intensity trends had leveled off (see Figure 7).

Figure 6 shows that growth was not equal among all manufacturing subsectors. Although not as important as declining energy intensities in restraining energy use, the changing structure of U.S. manufacturing has also played a significant role in shaping energy use trends. Over the entire study period real value added from ferrous metals, the most energy-intensive branch, actually declined. This, coupled with the fact that the strongest growth occurred in light manufacturing and chemicals, the "lightest" of the heavy industries, contributed to the rapid decline in aggregate energy intensity of U.S. manufacturing. However, this structural trend leveled off in 1985 and has remained steady ever since. It is interesting to note that throughout the study period, three energy-intensive industries pulp and paper, chemicals, and ferrous metals - have accounted for nearly $60 \%$ of the energy consumption in this sector. 
Figure 6. Shares of Manufacturing Value Added by Industry

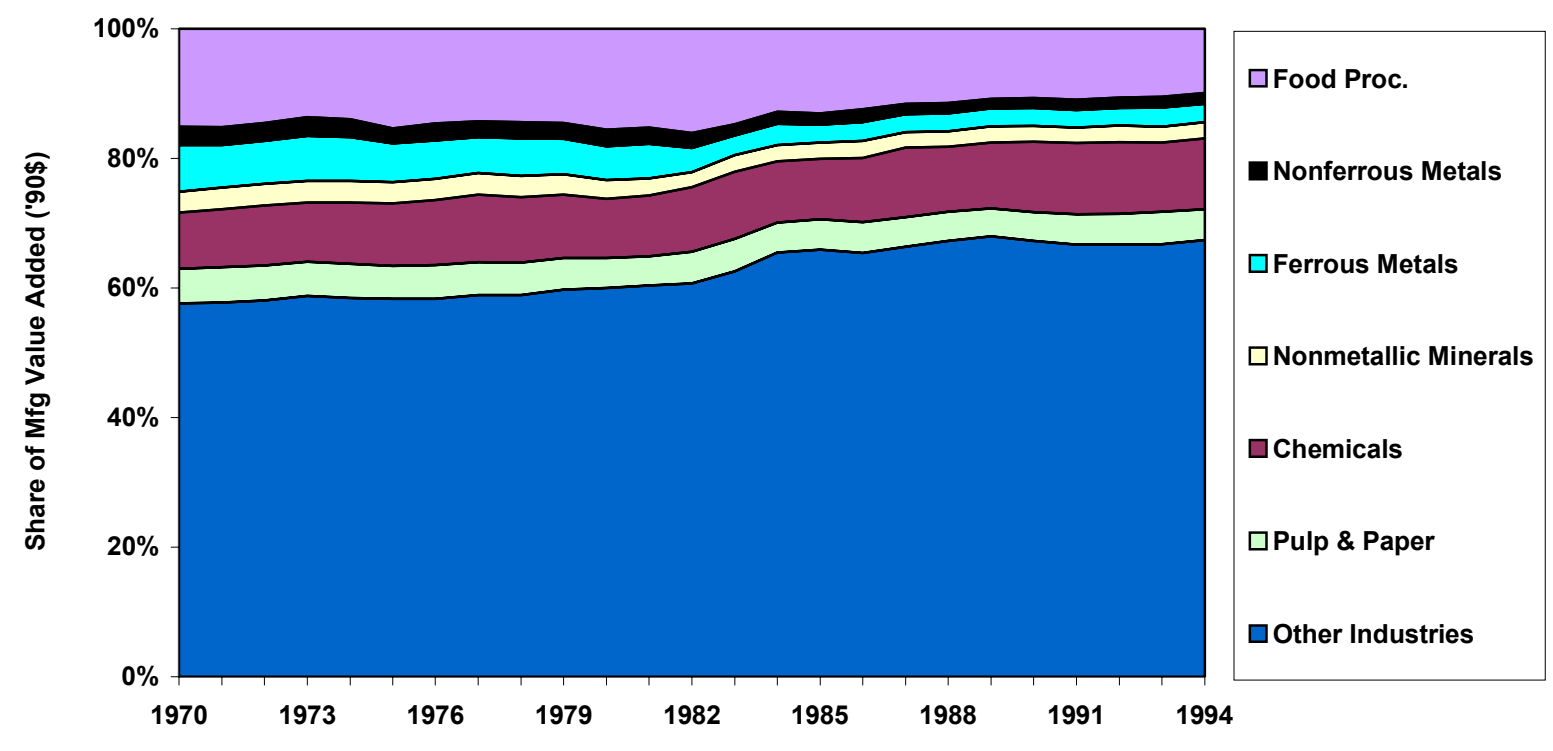

American manufacturers made impressive gains in decreasing energy intensities between 1970 and 1985. Figure 7 depicts the evolution of changes in energy intensity for each manufacturing branch or group as well as the fuel shares for each. Declines in energy intensity were much greater in some branches than others. Intensity declined most in chemicals, followed closely by nonmetallic minerals and other manufacturing industries. However, between 1985 and 1994 delivered energy intensity declined only in the pulp and paper, nonmetallic minerals, and ferrous metals industries while intensities in chemicals and food processing increased significantly. ${ }^{4}$ Increases for food processing are likely to be due largely to the decline in value added per unit of physical output. Through 1994, the 1990s were marked by almost constant energy intensities in terms of both delivered and primary energy. Thus, increasing output led to greater energy use. With the economic recovery since the mid1990 s, we expect to see that energy use will continue to climb, once official data on energy use by branch (for 1998) become available.

\footnotetext{
${ }^{4}$ A small, uncertain amount of the slight rise in intensities may be a result of increased interest in on-site generation of heat and power by individual firms. This would raise firms' apparent use of total energy, but by substituting on-site co-generated electricity for purchased electricity, reduce primary energy use. The savings occurs because the losses associated with purchased primary electricity tend to be much higher than those incurred in on-site cogeneration.
} 
Figure 7. Manufacturing Energy Intensities and Fuel Shares, Total and by Branch

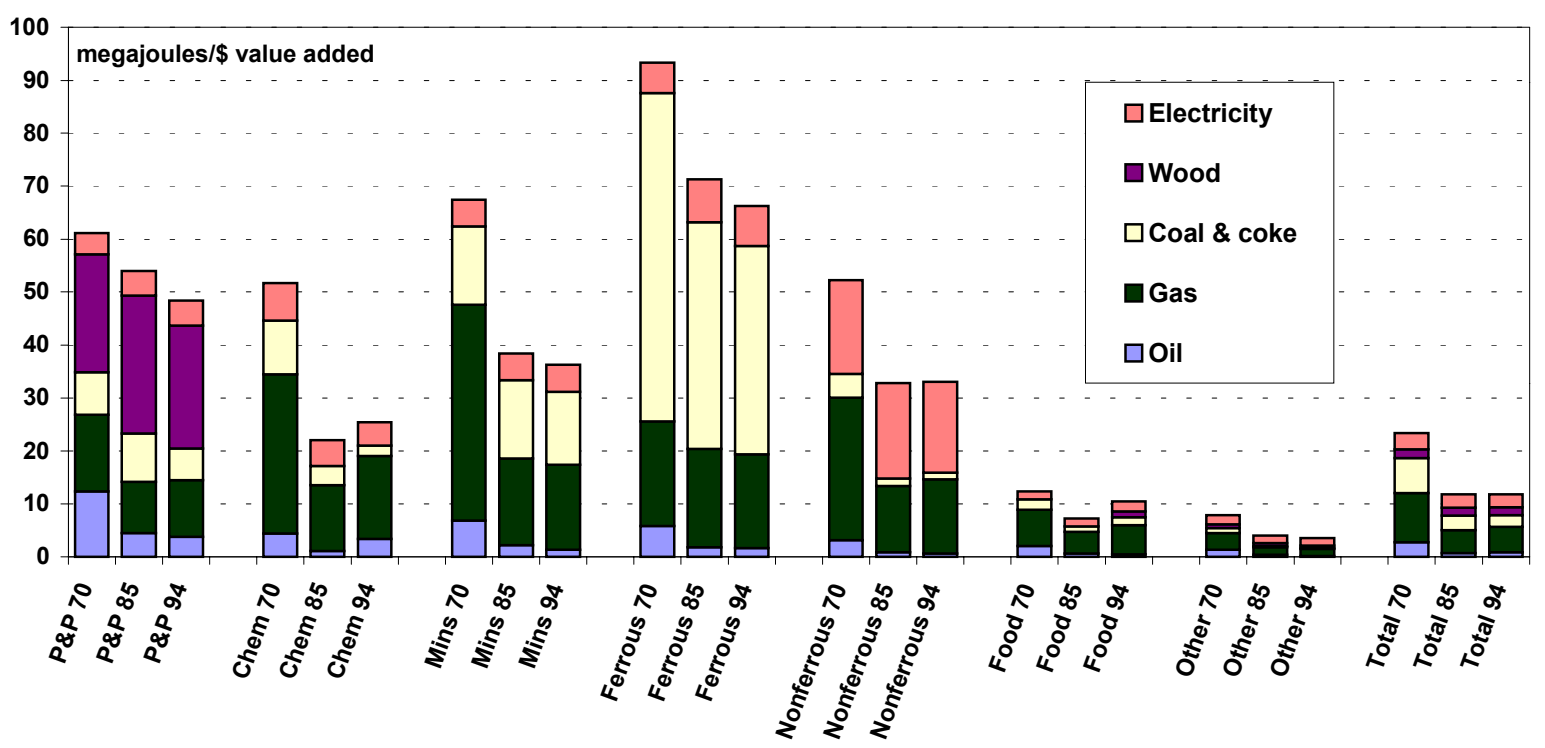

It is hard to say to what extent these trends in energy intensities may have been caused by structural shifts within these branches. Each of these categories encompasses several different products, particularly the other manufacturing grouping. As the mix of products shifted within these industry groupings this may have helped to decrease the amount of energy needed per value added for the industry as a whole.

Figure 8. Changes in Manufacturing Energy Use: Actual, and Decomposition Effects

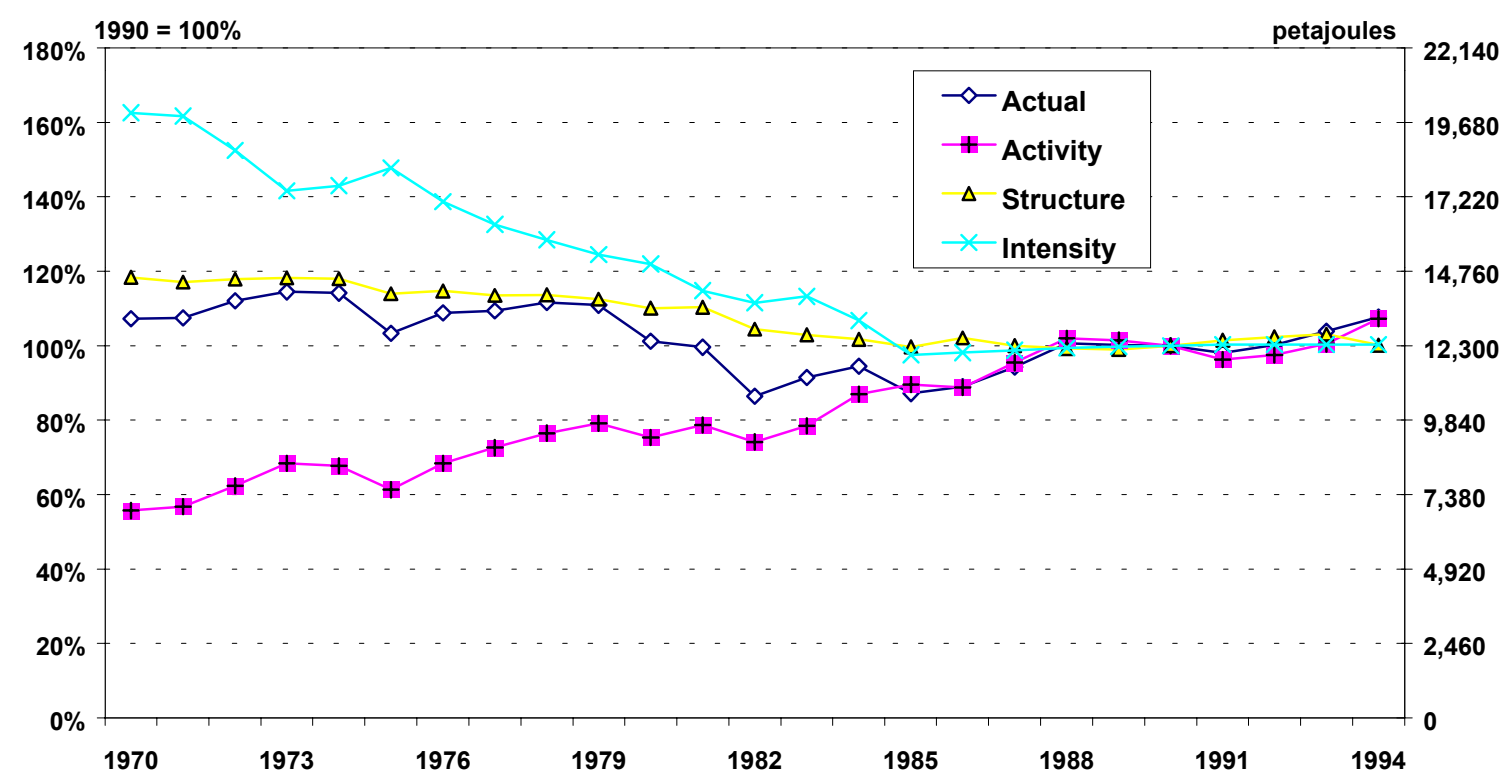

Figure 8 summarizes the results of the decomposition on delivered energy use. It reveals an important relationship between the two components that reduced energy use. In 1994, final energy use was over $35 \%$ lower than it would have been at 1970 intensities, while the "savings" from structural changes was $15 \%$. In other words, falling intensities saved almost 2.5 times more energy than structural change. Together, these two components negated the upward pressure on energy use from activity growth over the entire study period. However, since 1985, there has been almost no change in either the structure or intensity term. Consequently, energy use, driven by activity growth, has increased 
considerably. The interpretation of intensity changes is uncertain, because the only real data on consumption by branch are from 1988, 1991, and 1994. Moreover, 1991 was a near-recession year, which often tends to raise intensities somewhat due to lower capacity utilization. On the other hand, 1990 saw price increases related to the Gulf War. To fully gauge the trends of the early 1990s, data for 1998 will have to be examined carefully. If energy intensities do not begin to fall, the economic recovery of the 1990s may lead to significant increases in manufacturing energy consumption.

\section{NON-MANUFACTURING “OTHER” INDUSTRIES}

For the non-manufacturing industries actual delivered energy use in 1994 was only slightly higher than the 1970 level, climbing to almost 3,700 PJ from 3,500 PJ. Activity and structure effects remained relatively less important than in manufacturing. Partly this is the result of using economic measures of activity. Using value added as the metric for activity is more problematic for these industries since mining and agriculture both produce commodities, for which the relationship between physical output and value added has been more volatile than it has for manufactured products. The real prices of many commodities have dropped substantially over the study period. Thus the energy intensities we derived can be questioned: what is the meaning of the energy intensity of wheat or hog production if the number of bushels (or heads of cattle) increases while the value added declines? Unfortunately, there are no data disaggregating energy use for these commodities in such detail that would permit a physical description of energy intensities. Moreover, this monetary approach is a necessary weakness to allow for comparability of outputs across other parts of the productive economy.

\section{Box 2. Non-manufacturing “Other" Industries Sector Data Sources and Methodology}

Composition: This sector consists of NAICS categories 11, 21, and 23: Agriculture, Forestry, Fishing; Mining; and Construction.

Activity: Value added arising from the sector measured in real 1990 dollars from the National Income and Product Accounts.

Structure: Structure is measured as the relative amounts of GDP in each of the three subsectors

Intensity: Delivered (final) energy use per unit of value added or GDP.

Data: Energy use data are from the National Energy Accounts (1960-1985), and then from EIA's Annual Energy Outlook ${ }^{\text {xii }}$ historical data base (from 1993 onward). Close inspection of NEA reveals that a significant amount of natural gas used in mining and natural gas production, so called "lease and plant fuel" is excluded from NEA, so this was added to each year. For the years between 1986 and 1993, each fuel is interpolated in each sector on the basis of the ratio of that fuel to value added in 1985 and 1993 . While this method is only approximate, it represents the only known way of filling in for the missing values.

Energy use in other industries is dominated by petroleum products and natural gas (see Figure 9). Outside of the travel and freight sectors, other industries uses the lowest share of electricity, although this share has risen from $7 \%$ to $17 \%$. The growth in electricity consumption led to a $23 \%$ increase in primary energy consumption, while delivered energy use rose only $5 \%$. Trends in overall energy use and fuel shares are driven largely by mining, the most energy-intensive of these three industries. While mining accounted for only $22 \%$ of the value added in this sector in 1994 , it consumed $55 \%$ of the final energy and $85 \%$ of the natural gas. The drop in gas share after 1979 is due almost entirely to the rapidly declining energy intensity of the mining industry. 
Figure 9. Other Industries Energy Use by Fuel, with Electricity Losses

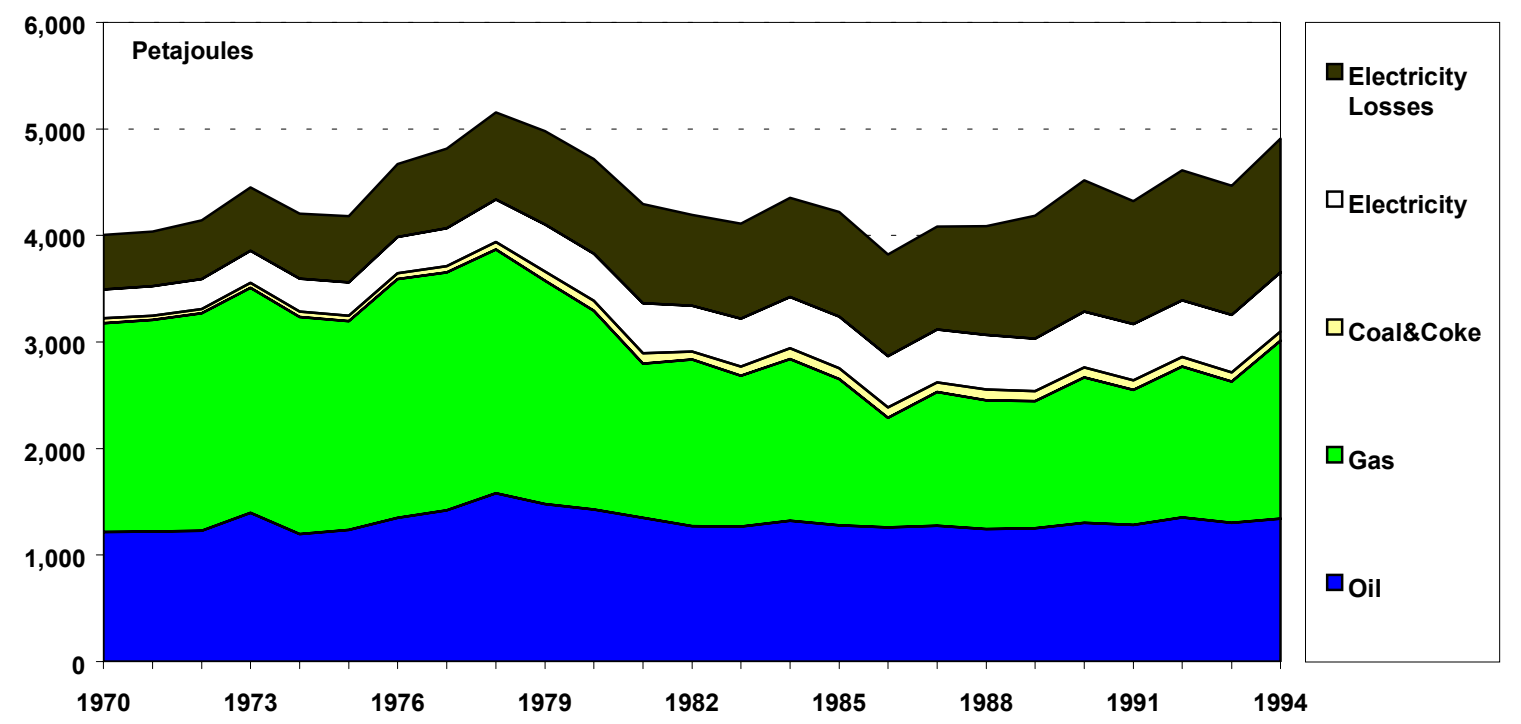

Value added remained fairly flat except for a sharp spike in growth from 1983 to 1985, during which each of the other industries experienced rapid growth. However, after 1985 agriculture was the only industry to continue showing significant value added growth (see Table 2). As a result of the stagnation in value added, other industries' share of GDP fell from $12 \%$ to $8 \%$ of the total.

Table 2. Other Industries Value Added and Delivered Energy Intensities

\begin{tabular}{|l|ccc|c|c|c|}
\hline \multirow{2}{*}{ Industry } & \multicolumn{2}{|c|}{ Value Added (Billion 1990 \$) } & \multicolumn{3}{c|}{ Delivered Energy Intensity (MJ/\$) } \\
\cline { 2 - 7 } & $\mathbf{1 9 7 0}$ & $\mathbf{1 9 8 5}$ & $\mathbf{1 9 9 4}$ & $\mathbf{1 9 7 0}$ & $\mathbf{1 9 8 5}$ & $\mathbf{1 9 9 4}$ \\
\hline Agriculture & 68.7 & 99.1 & 129.6 & 13.19 & 7.74 & 7.34 \\
Mining & 93.8 & 100.2 & 104.8 & 22.03 & 18.66 & 19.42 \\
Construction & 216.2 & 242.5 & 248.8 & 2.41 & 2.49 & 2.78 \\
\hline
\end{tabular}

Since construction accounts for over half of the value added in other industries, the trends in both the activity and structural effects have been largely driven by this industry. This explains why the trends in these components have moved in opposite directions, as Figure 10 demonstrates. Construction is by the far the least energy intensive of these industries. Thus, during periods when construction value added grows rapidly it will drive up the activity effect for the sector while rendering the sector less energy intensive in aggregate. The converse holds as well, but overall, the impact of the structure effect has been minimal.

Energy intensities in agriculture and mining have shown a pattern similar to that of many of the manufacturing industries. Intensities remained relatively flat during the 1970s and actually increased in mining. Then with the advent of the second oil price shock in 1979 intensities declined substantially until the mid-1980s. Average annual rates of intensity decline from 1979 to 1985 for agriculture and mining were $10 \%$ and $7 \%$ respectively. Intensity in construction, however, has changed very little. Construction is an extremely non-energy intensive industry, and since energy costs are relatively small, energy use is not likely to be responsive to energy prices. 
Figure 10. Changes in Other Industries Energy Use: Actual, and Decomposition Effects

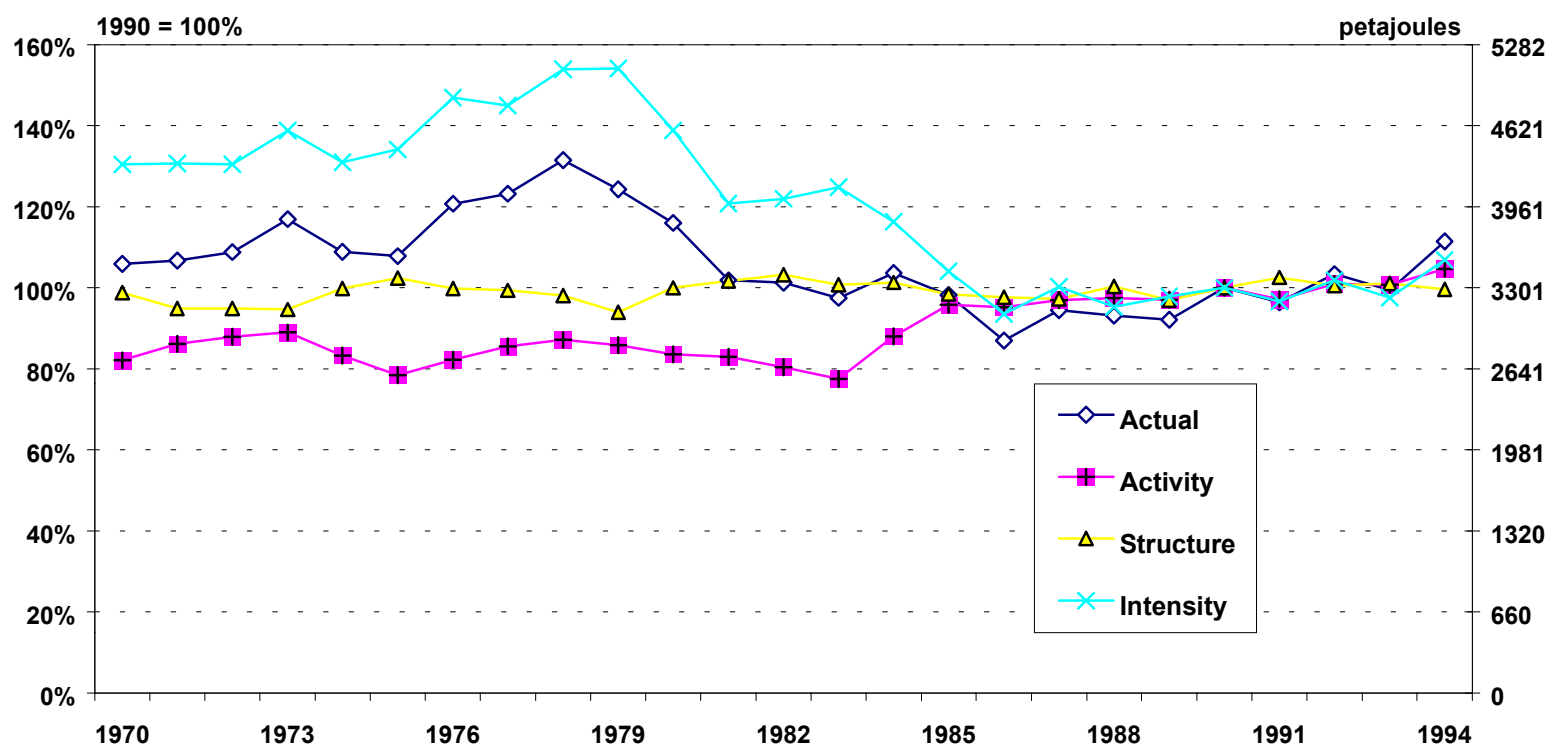

Figure 10 shows the results of the other industries decomposition. Note that intensities only declined briefly in these industries in the wake of the 1973 price shock, then continued to increase until the second price shock in 1979, when the aggregate other industries intensity reached its highest point. Over the next several years intensities declined rapidly in agriculture and mining, resulting in an energy savings of about $40 \%$ in 1986 compared to 1979 intensities. Subsequently both activity and intensity have edged up, pushing actual energy consumption back to the level of the early 1970s.

\section{SERVICES}

\section{Box 3. Services Sector Data Sources and Methodology}

Composition: This sector consists of NAICS categories $4-9$.

Activity: Value added arising from the sector measured in real 1990 dollars.

Structure: Floor area per real dollar (1990) of services value added.

Intensity: Delivered (final) energy use per floor area. This can be split into electricity and other energy forms for some purposes. Primary energy intensity is also used.

Data: Floor area is from the Commercial Buildings Energy Consumption Surveys ${ }^{\text {xiii }}$ (CBECS, formerly NBECS) from 1979 on (with a downward correction for the pre-1995 CBECS due to the exclusion of parking garages and commercial buildings on industrial sites that occurred in the 1995 CBECS) and from a Pacific Northwest National Laboratory time for previous years. Value added is from the National Income and Product Accounts. Energy use by fuel is from SEDR, with a correction for a small amount of residential oil consumption from large apartments counted as services, as noted by EIA.

The services economy has grown at a steady pace, accounting for an increasingly larger share of total U.S. GDP. During the period from 1970 to 1994 services GDP nearly doubled from three trillion to almost six trillion dollars, increasing its share from $68 \%$ to $73 \%$ of total GDP. 
Figure 11. Services Energy Use by Fuel, with Electricity Distribution Losses

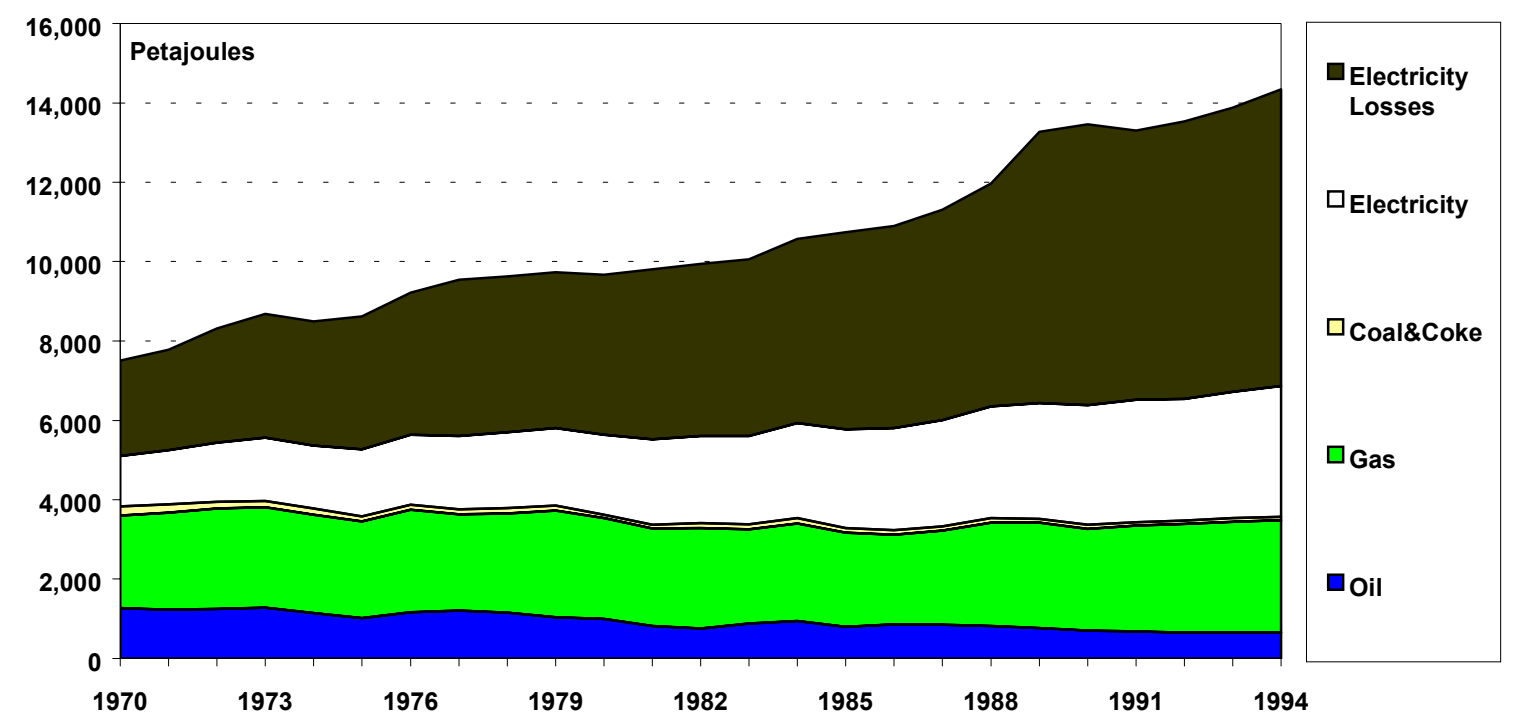

Energy consumption trends by fuel are given in Figure 11. The most important change in this sector has been the growth in the share of delivered energy provided by electricity, which increased from a quarter to about half of the final energy. Most of the electricity powered motors, lights, and office equipment, but some went to provide primary electric space heating. By 1995, electric heating had attained a $25 \%$ share of all heated floor area (CBECS), although electricity accounted for a much smaller share of energy consumed for heating. This is primarily because electrically-heated buildings are newer and located in warmer parts of the country. ${ }^{\text {xiv }}$ This electrification has a significant impact on the total primary energy used. While final energy use increased by about a third between 1970 and 1994, primary energy use increased by $90 \%$. Given this increase in space heated by electricity, the modest growth in electricity consumption is surprising: we would expect more, because buildings with electric heat tend to use significantly more electricity than those without.

Due to data limitations, we are unable to examine structural changes by service activity. We do know that the greatest growth in floor space has been among warehousing, office space, assembly buildings, and educational facilities. These structures are among the less energy-intensive building types in the services sector. The most energy-intensive structure types, health care, food service, and lodging, have experienced relatively slower growth in floor space. This structural change shows up as part of the declining average energy intensity indicator.

Our structural indicator shows that trends in floor space usage have also tended to drive up energy use. In 1970 service buildings occupied about 1.30 square meters for every $\$ 1000$ of annual value added. This ratio increased to about 1.53 by 1992 before declining sharply between 1992 and 1994 . However, the sharp reversal in the structure and intensity indicators after 1992 results from data showing a large decline in the total services floor area between 1992 and 1995, even with the correction for parking garages and commercial buildings on multibuilding industrial sites described in Box 3. More importantly, the 1995 CBECS reports significant declines in the floor area of office spaces, warehouses, and surprisingly, vacant buildings. Since this drop in floor space was not accompanied by a concomitant decline in either energy use or value added, the intensity and structural indicators are both strongly affected (see Figure 13). ${ }^{5}$

\footnotetext{
${ }^{5}$ The decline in services floor space reported in the 1995 CBECS may be due mostly to sampling error. For a discussion of these issues, see http://www.eia.doe.gov/emeu/consumptionbriefs/cbecs/cbecs_trends/buildings_floorspace.html.
} 
Figure 12 depicts the evolution of energy intensities, showing both fuel use (primarily heat) per sq. meter and electricity use per sq. meter (in delivered energy terms) over time. In spite of huge increases in electricity services in buildings, electricity intensity increased by less than $50 \%$ from 1970 to 1988, and remained quite stable thereafter. This increase had to cover the requirements of a growing share of electric space heating, great increases in the share of space air conditioned, as well as all of the information and communications technology adopted by service industries during this time. Most of this electricity used for information technology and other electronic applications also produces a significant amount of incidental heat, as it is converted to low-temperature heat in motors, computers, lights, etc. CBECS shows that heating intensities for gas, electricity, and oil in buildings heated principally by those fuels fell between 1979 and 1995. How much of this decline in oil or gas intensity was saved heat, and how much of that was indirectly provided by waste heat from other uses is uncertain, but the overall savings appear real. The overall decline in non-electricity (fuel) intensities of almost $0.5 \mathrm{GJ} / \mathrm{sq}$. meter is greater than the total increase in electricity use of $0.17 \mathrm{GJ} / \mathrm{sq}$. meter. Since only a small part of that electricity is for heating, the balance of the decline in fuel intensity must be from saving heat.

\section{Figure 12. Service Sector Intensities}

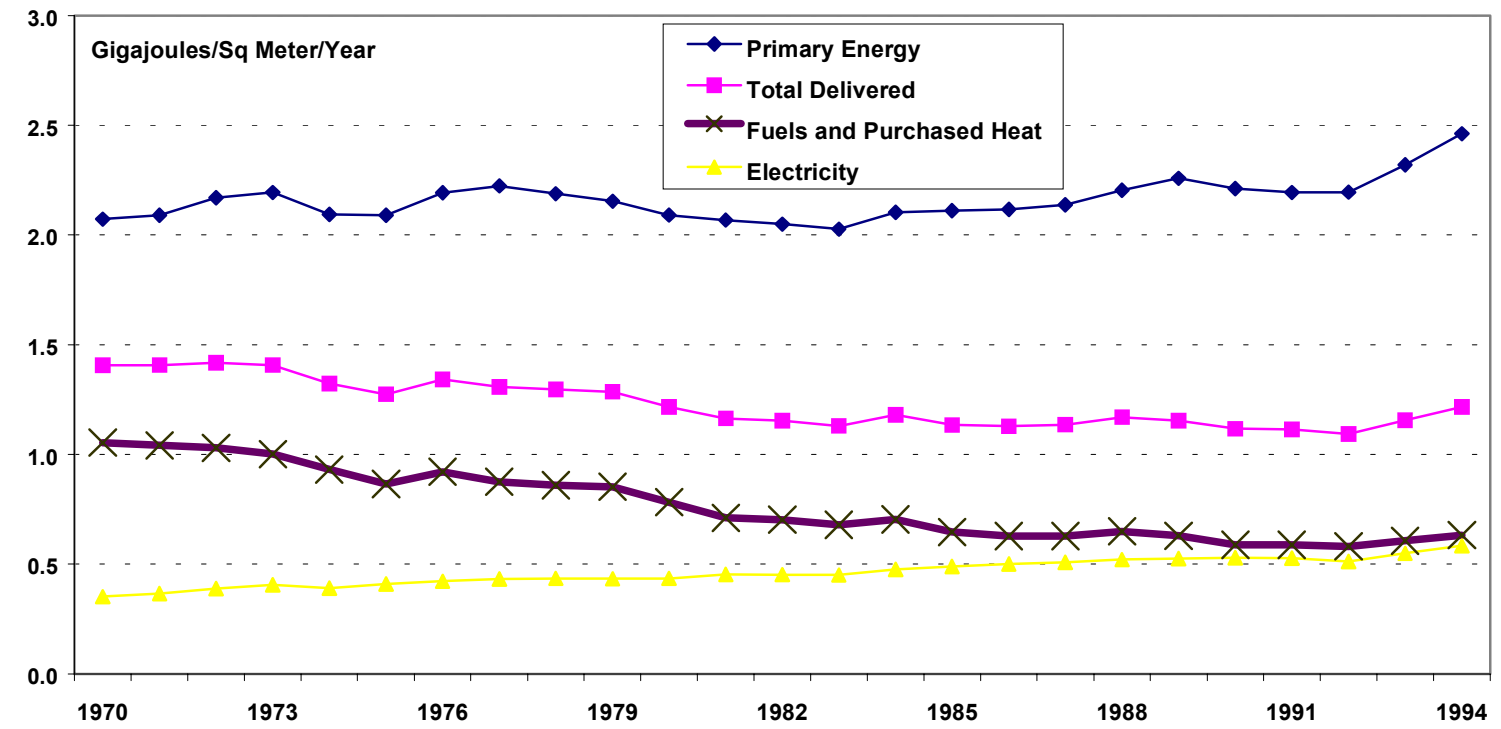

Data limitations constrain the analysis of the service sector in this report. Nevertheless, the trends indicate a significant saving of heat from fuels, and implicitly an important saving of electricity in heating and in other applications. In primary terms, intensity is flat - the upturn in the early 1990s being related mostly to changes in the ratio of electricity delivered to primary energy consumed by utilities. 
Figure 13. Changes in Services Building Energy Use: Actual, and Decomposition Effects

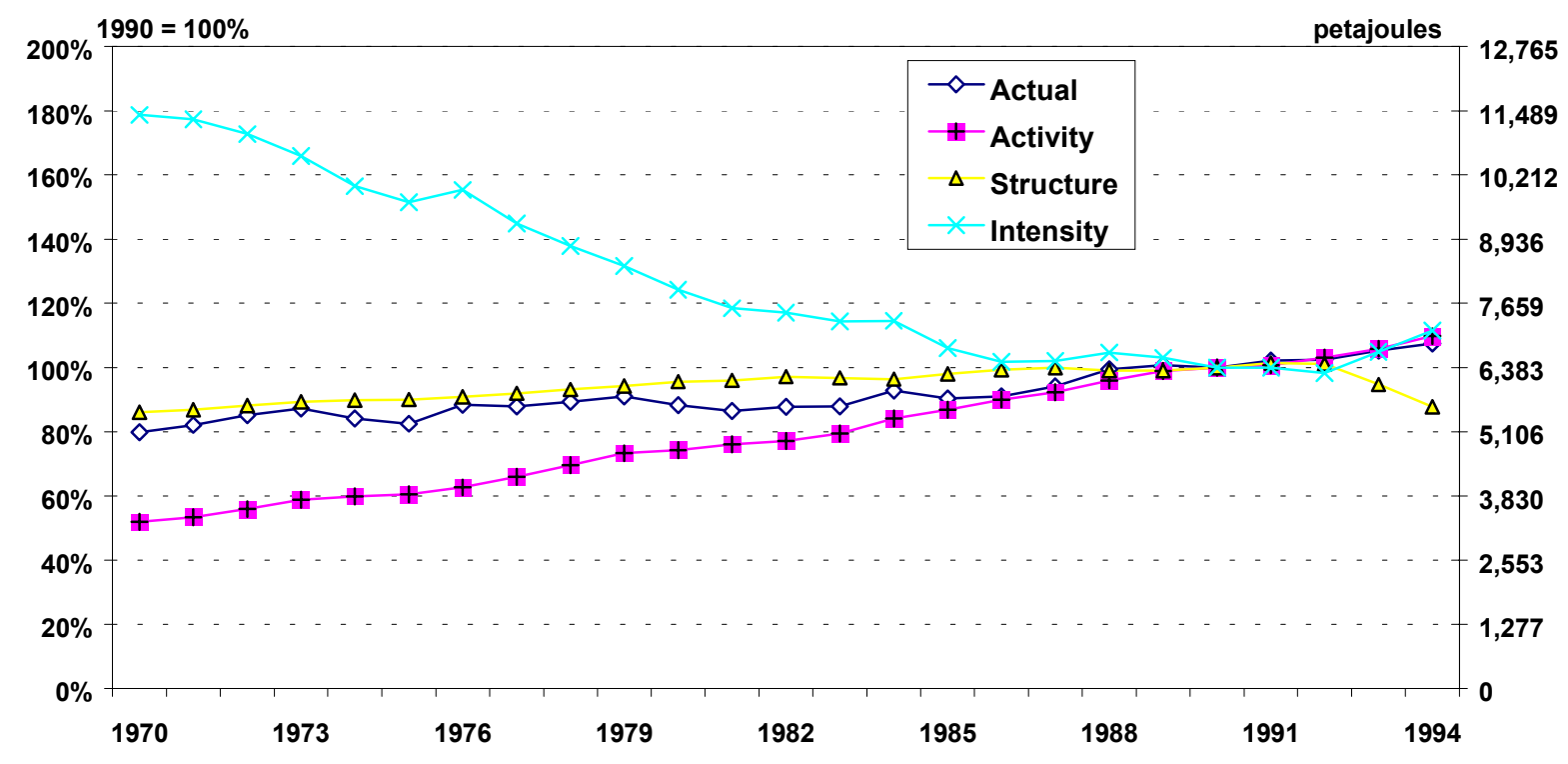

The results of our decomposition are shown in Figure 13. This decomposition shows that changes in final energy intensity and economic activity have largely offset each other since 1970. Energy intensity fell steadily throughout the study period, until the early 1990s. However, this is due to the decline in floor space reported in the 1995 CBECS. The real intensity improvements that have occurred are probably largely due to improvements in the insulation of building shells as well as structural changes occurring below the level of aggregation used in our study. 


\section{RESIDENTIAL}

\section{Box 4. Residential Sector Data Sources and Methodology}

End-Uses: Residential space heating, water heating, cooking, six major appliances, miscellaneous appliances, and lighting.

Useful energy: As an approximation of the amount of heat that emanates from a space heater, boiler or furnace to a house or to water. Equal to delivered energy in electricity, $66 \%$ of delivered energy of gases and liquids, and 55\% of delivered energy in coal, wood or other solids. It is important to differentiate between useful and delivered energy so that fuel switching for certain end-uses does not appear as an energy savings when a real decline in intensity has not occurred.

Activity: Population

Structure: Per capita house area for space heating and lighting, index of square root of family size for cooking and water heating, per capita appliance ownership.

Intensity: Useful energy and delivered energy use per square meter per degree-day for space heat. Energy per capita for water heating and cooking. Annual energy consumption by type of appliance. Lighting energy per square meter of floor area.

Data: Households and occupied dwellings are considered equal. Data are taken from the Census, the American (formerly Annual) Housing Survey ${ }^{\mathrm{xv}}$, and the Residential Energy Consumption Surveys (RECS). ${ }^{\text {xvi }}$ Appliance ownership and other housing characteristics are from RECS, with the LBNL Model Data based used for years prior to 1978. Heating systems are from the 1970 Census, Dole $(1975)^{\text {xvii }}$ for 1970, and Newman and Day ${ }^{\text {xiii }}$ for 1973. Central heating is defined as all boilers or furnaces serving main rooms, fixed electric baseboard heating, and heat pumps. Stove heating is defined as one or more independent room stoves, fireplaces, or loose electric heaters. Floor area is from RECS. Data for 1970-1978 were estimated by noting the size of the pre-1970 stock in the 1978 RECS survey and interpolating through 1980.

Energy end uses are taken from RECS estimates after 1980, from Dole for 1970 and Newman and Day for 1973, and interpolated for other years. Unit consumption for appliances is from the LBNL model for the 1970 s and subsequently from RECS. 
Figure 14. Residential Energy by Fuel (Climate Corrected), with Electricity Transformation and Distribution Losses

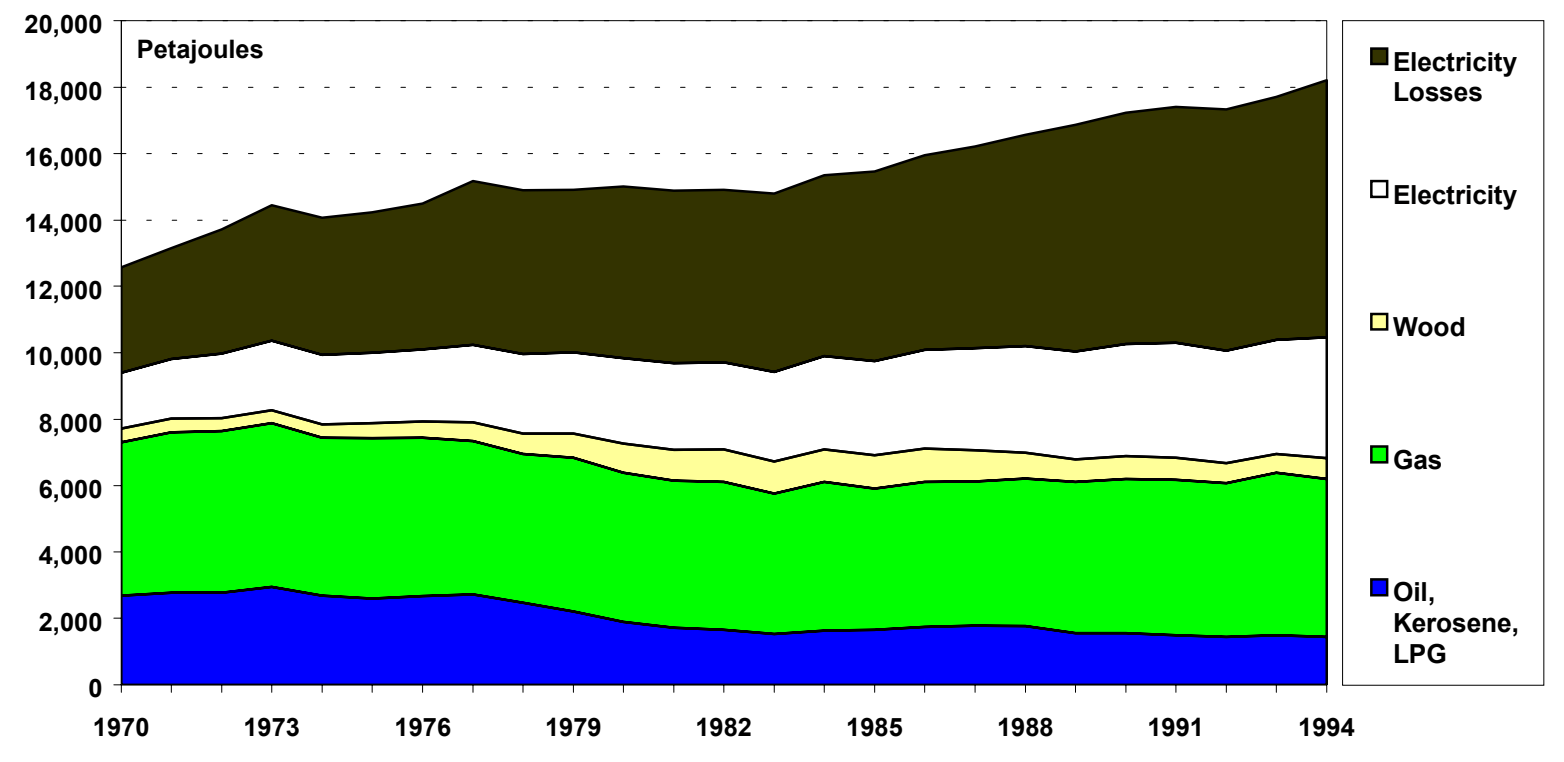

Delivered energy ${ }^{6}$ use in the U.S. residential sector has changed very little since 1970 (Figure 14). Energy use rose from 1970 to 1973 when the oil price shock induced a variety of conservation measures. The decline in energy intensity that began in 1973 continued during most of the study period and effectively offset the upward pressure on energy use due to other factors. By 1994 delivered energy consumption was only 8\% higher than it had been in 1970 .

Fuel shares in the residential sector have changed markedly since 1970. As is evident from Figure 14, the biggest changes occurred in the relative shares of oil and electricity. This occurred primarily for two reasons. First, oil lost share among multi-fuel end-uses: space heating, water heating, and cooking. Second, the increasing saturation of appliances has also served to increase demand for electricity relative to other fuels. The share of appliances in total demand for final energy increased steadily over the study period from $9 \%$ to $21 \%$. About $75 \%$ of the growth in electricity is accounted for by appliances and lighting. This means that only a small part $-25 \%$ - of the increase for electricity is due to using electricity today where fuels were used in the past, i.e., for space and water heating and cooking.

As the share of electricity has increased, this has had two contradictory effects on other measures of energy use. It diminished the demand for delivered energy because most of the delivered energy in electricity is applied to the end-use, whereas much of the energy from direct fuel combustion is lost. Thus, a greater share of electricity for these multi-fuel end-uses implies lower demand for delivered energy. However, increasing shares of electricity entail stronger growth in demand for total primary energy due to the large losses of energy from conversion and distribution. Electrification of the residential sector has had enormous consequences for primary energy use - while final energy increased only by $8 \%$, primary energy consumption jumped $46 \%$.

The end uses of energy in the residential sector have changed considerably. Figure 15, which depicts residential energy use per capita, by end-use, as well as the 1970 and 1994 shares by end-use (the

\footnotetext{
${ }^{6}$ Note that delivered energy data for the residential sector have been climate corrected for space heating by adjusting heating energy consumption to average annual heating degree-days.
} 
right hand columns). This figure suggests that declining intensities for space heating have resulted in space heating accounting for a lower share of energy use, while per capita appliance energy demand doubled. Note that most of the energy savings suggested in Figure 15 originate from declining energy intensity for space heating.

Figure 15. Residential Delivered Energy Use per Capita by End-Use

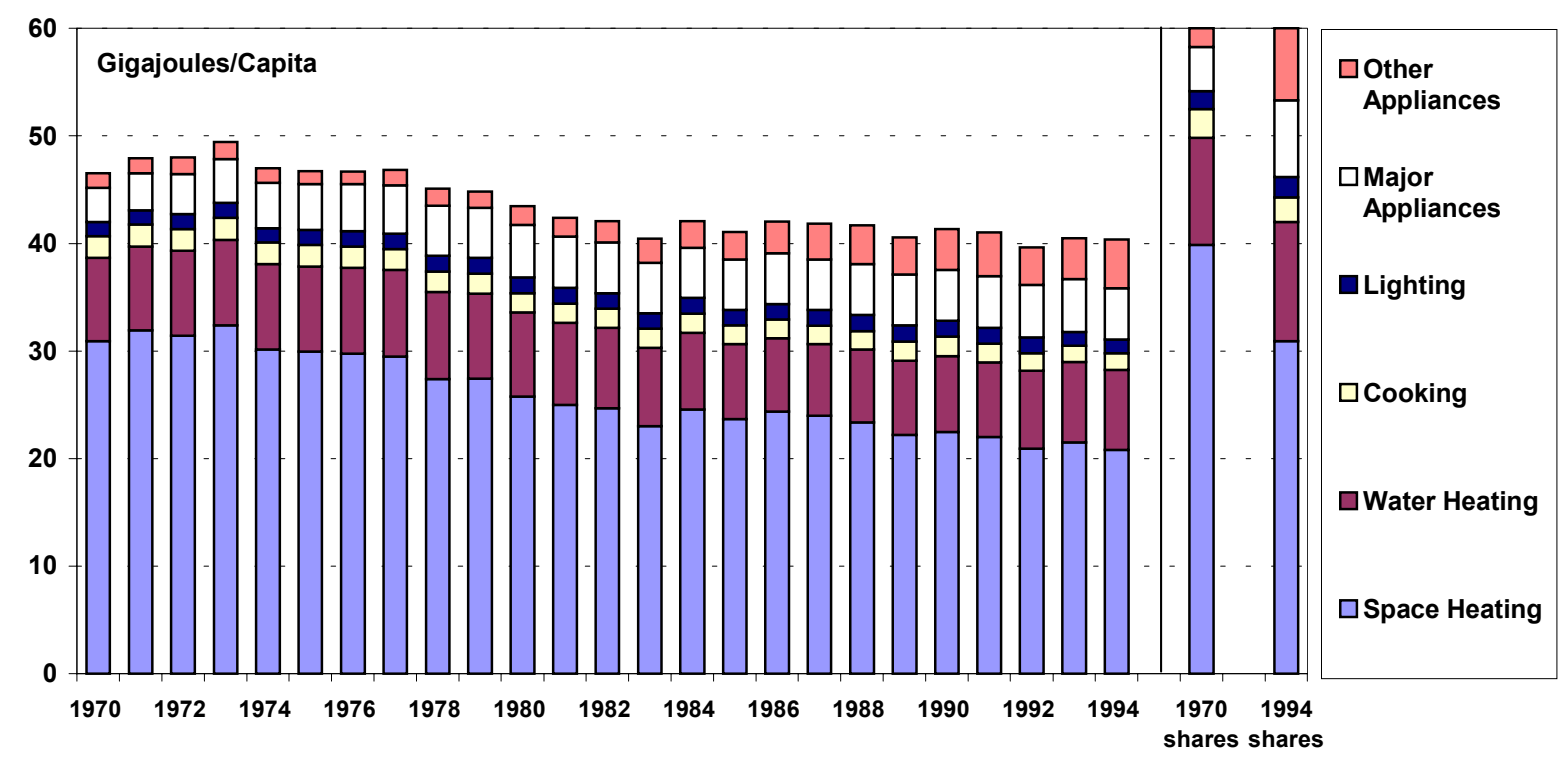

Several important structural trends have strongly influenced residential energy use. Table 3 lists the changes in two structural parameters that affect energy use from several end-uses. Home floor area is a key driver of space heating, cooling, and lighting. Americans enjoy large home sizes relative to other OECD countries. ${ }^{7}$ The average amount of dwelling space per capita has been rising continuously except for a brief period in the early to mid-1980s when per capita home size remained level. Figure 16 depicts apparent saturation of per capita dwelling area, which is growing less rapidly with respect to the measure of income, personal consumption expenditures. (The slope of the diagonal line bisecting the chart area corresponds to a constant response ratio of area to income.) This is an important structural change that reduces the heating needs of the country, relative to GDP. Still, the increase in overall area presents a challenge to energy conservation efforts as the increase in home size exerts more pressure on energy use for space heating, cooling, and lighting. ${ }^{8}$

Table 3. Change in Terms Affecting Residential Enery Use

\begin{tabular}{|c|c|c|c|c|c|c|c|}
\hline \multirow[b]{2}{*}{ Year } & \multicolumn{3}{|c|}{ Activity \& Structure } & \multicolumn{4}{|c|}{ Intensities (in Useful Energy) } \\
\hline & $\begin{array}{c}\text { Population } \\
\text { (millions) }\end{array}$ & $\begin{array}{c}\text { Htd Area/ } \\
\text { Cap }\left(\mathrm{m}^{2}\right)\end{array}$ & $\begin{array}{l}\text { Persons/ } \\
\text { Dwelling }\end{array}$ & $\begin{array}{c}\text { Lighting } \\
\mathrm{MJ} / \mathrm{m}^{2}\end{array}$ & $\begin{array}{l}\text { Space Htg } \\
\left(\mathrm{KJ} / \mathrm{m}^{2} / \mathbf{d d}\right)\end{array}$ & $\begin{array}{l}\text { Cooking } \\
\text { GJ/Cap }\end{array}$ & \begin{tabular}{|c} 
Water Htg \\
GJ/Cap
\end{tabular} \\
\hline 1970 & 205 & 43 & 3.18 & 30 & 184 & 1.7 & 5.5 \\
\hline 1985 & 239 & 50 & 2.76 & 29 & 120 & 1.6 & 5.1 \\
\hline 1994 & 261 & 57 & 2.67 & 22 & 97 & 1.6 & 5.2 \\
\hline
\end{tabular}

\footnotetext{
${ }^{7}$ In 1994, U.S. dwelling size per capita was $57 \mathrm{~m}^{2}$, compared to $54 \mathrm{~m}^{2}$ in Sweden, $41 \mathrm{~m}^{2}$ in Canada, $35 \mathrm{~m}^{2}$ in France and the U.K., and $33 \mathrm{~m}^{2}$ in Japan.

${ }^{8}$ From 1978 total house area is taken from RECS. For years before 1978, the size of the pre-1978 stock as given in RECS 1978 and 1980 (actually given as pre-1970 and pre-1975) is used to estimate the are of the stock in 1970 and 1975 , and intervening years are interpolated.
} 
The declining number of occupants per household has also influenced residential energy use, since this requires a larger number of dwellings to house a given population. A decline in the number of occupants per household has the effect of both lowering the amount of energy used per household for water heating and cooking and increasing the number of water heaters and ranges per capita. Because there are "economies of scale" for energy use in cooking and water heating, the amount of energy consumed does not decrease linearly with the number of occupants per household. Thus, a decline in occupants per dwelling has the net effect of increasing energy use per capita. Based on data from the U.S., the Netherlands, and Sweden, Schipper et al. ${ }^{\text {xix }}$ estimated that energy use for water heating, cooking, and appliances tends to grow with approximately the square root of household size, which implies that per capita energy use increases with the inverse of the square root of household size. If actual consumption changes more slowly than with the inverse square root of household size, we attribute the difference to energy saving. We estimate that this trend has had the effect of increasing energy use per capita from these end-uses by about 10\% from 1970 .

\section{Figure 16. Personal Consumption Expenditures vs. Dwelling Area per Capita, 1970-1997}

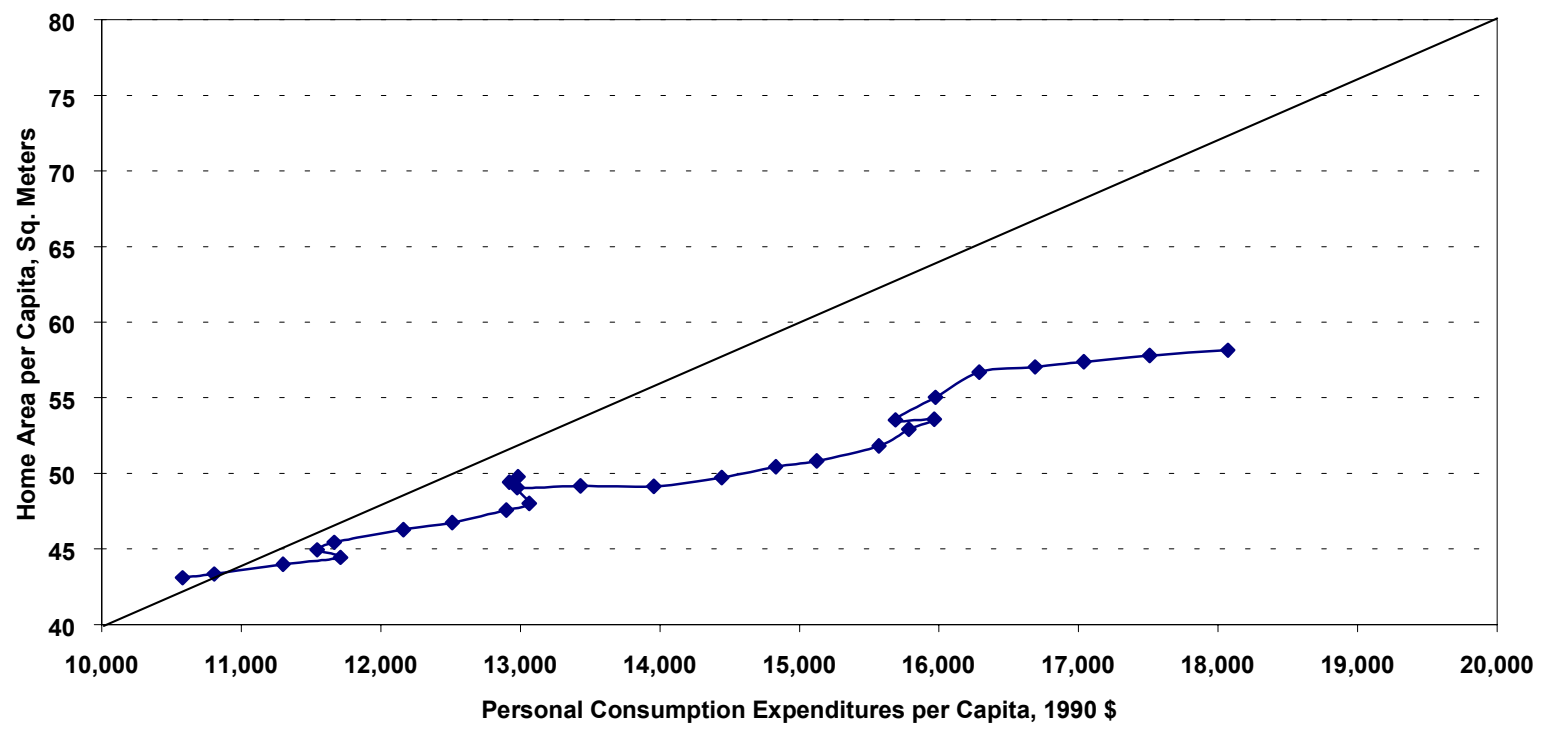

The key structural changes listed in Table 3, coupled with population growth, have led to a $63 \%$ increase in the demand for energy services as defined in the first part of this report. First, the average dwelling size increased from 137 square meters to 152 square meters, with most of this increase occurring since the late 1980s. Second, the U.S. population increased over $27 \%$. Third, the average number of occupants per dwelling decreased from 3.18 to 2.67. Together, these three trends resulted in an expansion of total residential floor area of nearly $70 \%$ to the current level of over 14.8 billion square meters. Additionally, the percentage of residences with central heating increased from $68 \%$ to $84 \%{ }^{9}$ This development is often overlooked, but is known to be associated with a near doubling of energy use for heating, compared to using individual room stoves (Schipper, Ketoff and Kahane 1985). ${ }^{\mathrm{xx}}$

Counteracting these structural pressures toward increased energy consumption, is the pronounced reduction in space heating intensities and, to a much smaller extent, lighting intensity. Space heating

\footnotetext{
${ }^{9}$ Central heating is defined as either a warm air furnace or hot-water boiler powered by fossil fuels, district heat, direct electricity, or a heat pump providing heat to all major rooms, or fixed electric heaters in a majority of rooms. Floor and wall stoves, loose electric heaters, and fireplaces that are considered in the RECS survey as principal heating sources are not considered central heating systems.
} 
intensity fell by nearly a half, resulting in a savings of over 5,100 PJ of delivered energy in 1994. When cooking and water heating energy per capita is examined, we find that they have not changed appreciably. Efficiency of water heaters may have improved, however structural changes in the ownership levels of appliances that use hot water have increased the demand for hot water. Changes in cooking energy are complex because they are closely related to behavioral factors such as increases in number of meals eaten outside the home, greater consumption of pre-prepared foods, and greater use of microwaves (which is not currently counted as cooking energy use, but is classified under "appliances").

Trends in appliance ownership have also contributed to the demand for energy services, particularly the increasing saturation of appliances, shown in Table 4. The most important of these has been the rapidly growing saturation of air conditioning (AC) units, which have achieved a saturation level of $86 \%$, up from about $40 \%$ in 1970 . Since air conditioners are the most energy intensive of the appliances, this growth has exerted strong pressure on energy use, and with the share of central AC in the total growing, average unit energy consumption (UEC) declined very little. The energy use stemming from only the increase in $\mathrm{AC}$ saturation accounted for about $7 \%$ of all residential electricity used in 1994 or about $4 \%$ of the total primary energy consumption. The appliance with the largest relative gain in saturation is dishwashers, largely because relatively few households had dishwashers in 1970. Currently about half of households have dishwashers, but dishwashers consume relatively little energy and since dishes are washed at home anyway, the balance of hot water use changes little with the advent of machines. However, the increasing ownership of clothes-washers increases demand for hot water, so a considerable portion of its energy use is indirect. The UEC shown only counts the energy use of the motors.

Growth in clothes-dryer ownership has also contributed to residential electricity use. Dryers are one of the most electricity-intensive appliances, ranking only behind air conditioners and refrigerators for annual energy consumption. They are now found in more than half of all dwellings, up from about a quarter of residences in 1970. These structural trends are likely to continue increasing the demand for residential energy, as newer housing stock tends to be larger, centrally heated and cooled, and designed to include dishwashers and laundry facilities.

A considerable amount of electricity growth has resulted from increased ownership of novel small appliances (such as microwaves) and electronics that did not exist or were not commonly owned in the early 1970s. Lacking any hard data on these uses for the 1970s, we can only illustrate how "miscellaneous appliances" has grown. Miscellaneous appliances accounted for over 914 PJ in 1994 vs. only 236 PJ in 1970. This figure is only a residual after other electricity uses are counted (i.e., space and water heating, cooking, lighting, and major appliances.). A more detailed study projecting strong growth in consumption by miscellaneous end-uses (Sanchez et al 1998) ${ }^{\mathrm{xxi}}$ suggests this consumption should be examined more closely and monitored carefully.

Table 4. Unit Energy Consumption and Saturations of Major Appliances

\begin{tabular}{|l|c|c|c|c|c|c|}
\hline \multirow{2}{*}{ Appliance } & \multicolumn{2}{|c|}{ Unit Energy Consumption (kWh) } & \multicolumn{3}{c|}{ Saturation } \\
\cline { 2 - 7 } & $\mathbf{1 9 7 0}$ & $\mathbf{1 9 8 5}$ & $\mathbf{1 9 9 4}$ & $\mathbf{1 9 7 0}$ & $\mathbf{1 9 8 5}$ & $\mathbf{1 9 9 4}$ \\
\hline Refrigerators & 1316 & 1292 & 1033 & $93 \%$ & $116 \%$ & $120 \%$ \\
Freezers & 1430 & 1198 & 857 & $28 \%$ & $36 \%$ & $37 \%$ \\
Washers & 102 & 110 & 103 & $72 \%$ & $77 \%$ & $84 \%$ \\
Dryers & 1006 & 1009 & 935 & $27 \%$ & $49 \%$ & $55 \%$ \\
Dishwashers & 346 & 178 & 157 & $19 \%$ & $46 \%$ & $48 \%$ \\
Air Conditioners & 1924 & 1790 & 1929 & $40 \%$ & $63 \%$ & $73 \%$ \\
\hline
\end{tabular}

The UEC data for washing machines is for the motor only. It does not count the energy used for water heating. 
The UECs of certain appliances, particularly freezers and dishwashers, have exhibited sharp declines. Significant energy conservation also resulted from energy intensity improvements in refrigerators, air conditioners, and dryers. The only end-use not to have shown any improvement is washing machines. Much of the energy use for this appliance is indirect - the energy used to heat water - and is counted in water heating. Thus, some improvements to reduce hot water use - lower wash temperatures, lower water needs - may have helped to conserve energy, but this will not be revealed by the UEC data for washing machines. Countering this trend is the increased ownership of washing machines replacing washing at laundromats, which would increase home hot water use.

\section{Figure 17. Changes in Residential Energy Use: Actual and Decomposition Effects}

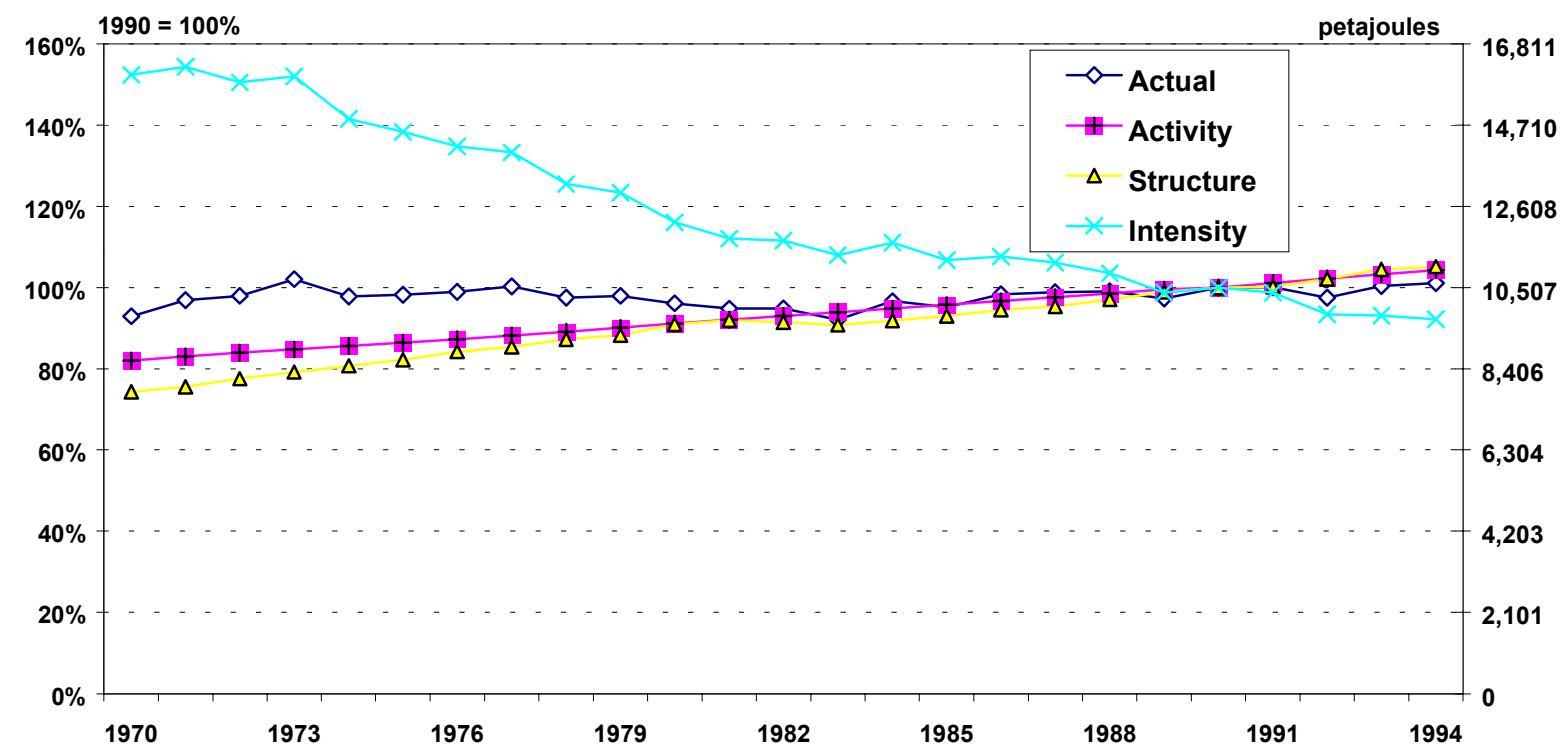

Figure 17 depicts the results of the residential decomposition, which shows that despite upward pressure on demand for energy services, actual energy consumption remained relatively even. This happened as a result of the remarkable decline in energy intensities for several end uses during this time. Space heating intensity declined most, falling by nearly half, but the intensities of major appliances have fallen since the mid 1980s as well. Structural trends have had a major upward impact on household energy use, raising it by nearly a third since 1970. The 1990-1994 period shows a return to the slow increase in delivered energy use, mostly because energy intensities are falling more slowly. The slowing of some structural trends suggests that the U.S. may be approaching saturation of many appliances and central heating. 


\section{Travel (Passenger Transportation)}

\section{Box 5. Travel Sector Methodology and Data Sources}

Sector end uses: Passenger cars, light commercial vehicles used for private travel, buses, domestic rail and subway/trams, and domestic air travel.

Activity: Travel measured in passenger kilometers (pkm), and vehicle kilometers (vkm) for some indicators concerning cars.

Structure: The shares of total travel (in pkm) accounted for by each of the modes.

Intensity: Vehicle intensity is energy use/vkm; modal intensity is energy use/pkm.

Data Sources. Almost all figures are taken from the Oak Ridge National Laboratory (ORNL) Transportation Energy Data Book ${ }^{\text {xxii }}$, the National Transport Statistics ${ }^{\text {xxiii }}$, the Nationwide Personal Transportation Surveys ${ }^{\text {xiv }}$ (load factors for automobiles), and for 1970, from a report by Mutch of the Rand Corporation. ${ }^{\mathrm{xxv}}$

Activity for light trucks attributed to passenger movements is taken from the Truck Inventory and Utilization Surveys (TIUS) of 1972, 77, 82, 87, and from the revised 1992 and 1997 values in the Vehicle Inventory and Utilization Survey (VIUS). ${ }^{\text {xxi }}$ Numbers of light trucks used as passenger vehicles are from the same source. Energy intensity is taken as the same as that for all light trucks. (For 1997, this figure is 7\% higher than the estimate made by ORNL). This definition differs from that of EIA, who split light trucks into commercial vehicles (over $8800 \mathrm{lbs}$.) and non-commercial vehicles and lump the latter with cars.

Energy use and travel for domestic aviation excludes domestic-owned carriers departing the U.S Actual fuel consumption is total fuel consumption minus the estimate for air freight provided by $\mathrm{D}$. Chien of EIA from his historical analysis and AEO model.

Energy use in personal travel has increased considerably since 1970. Actual energy use increased by $37 \%$ during this time, driven largely by increasing activity. Figure 18 depicts both the change in total energy use (scaled to the right hand axis) as well as per capita energy use disaggregated by mode. Energy use per capita has increased only $12 \%$, which indicates that much of the increase in travel activity is due simply to population growth. Figure 18 makes it apparent that modal energy use has not grown evenly. While per capita energy consumption declined for rail and buses ${ }^{10}$ combined, it increased about $5 \%$ for cars/light trucks and over 30\% for air travel.

10 "Buses" includes intercity, local transit, and school buses. 
Figure 18. Travel Delivered Energy Use, Total and per Capita by Mode

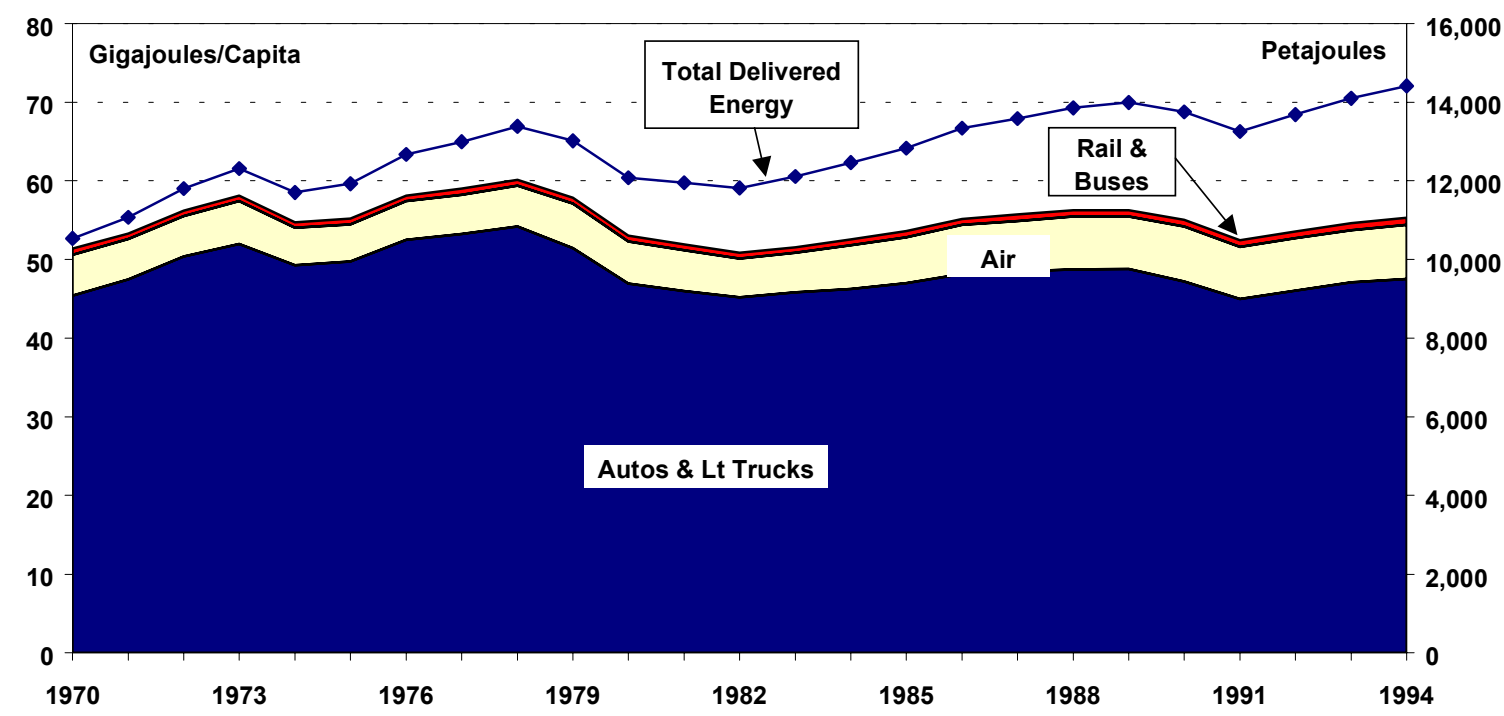

Overall, energy use increased less rapidly than activity. Total pkm has increased steadily at an average rate of $2 \%$ per year over the 1970 level, an increase of $57 \%$ between 1970 and 1997 . Activity only declined briefly in the two or three years immediately following the oil price shocks. Figure 19 confirms the structural trends suggested above in Figure 18. Air travel activity has increased much more rapidly than it has in the other modes. Air pkm nearly quadrupled while that of the other modes increased by about $50 \%$. This resulted in air travel carrying $13 \%$ of pkm in 1994 , compared to only $5 \%$ in 1970 .

Figure 19. Travel Activity by Mode, with 1970 and 1994 Shares

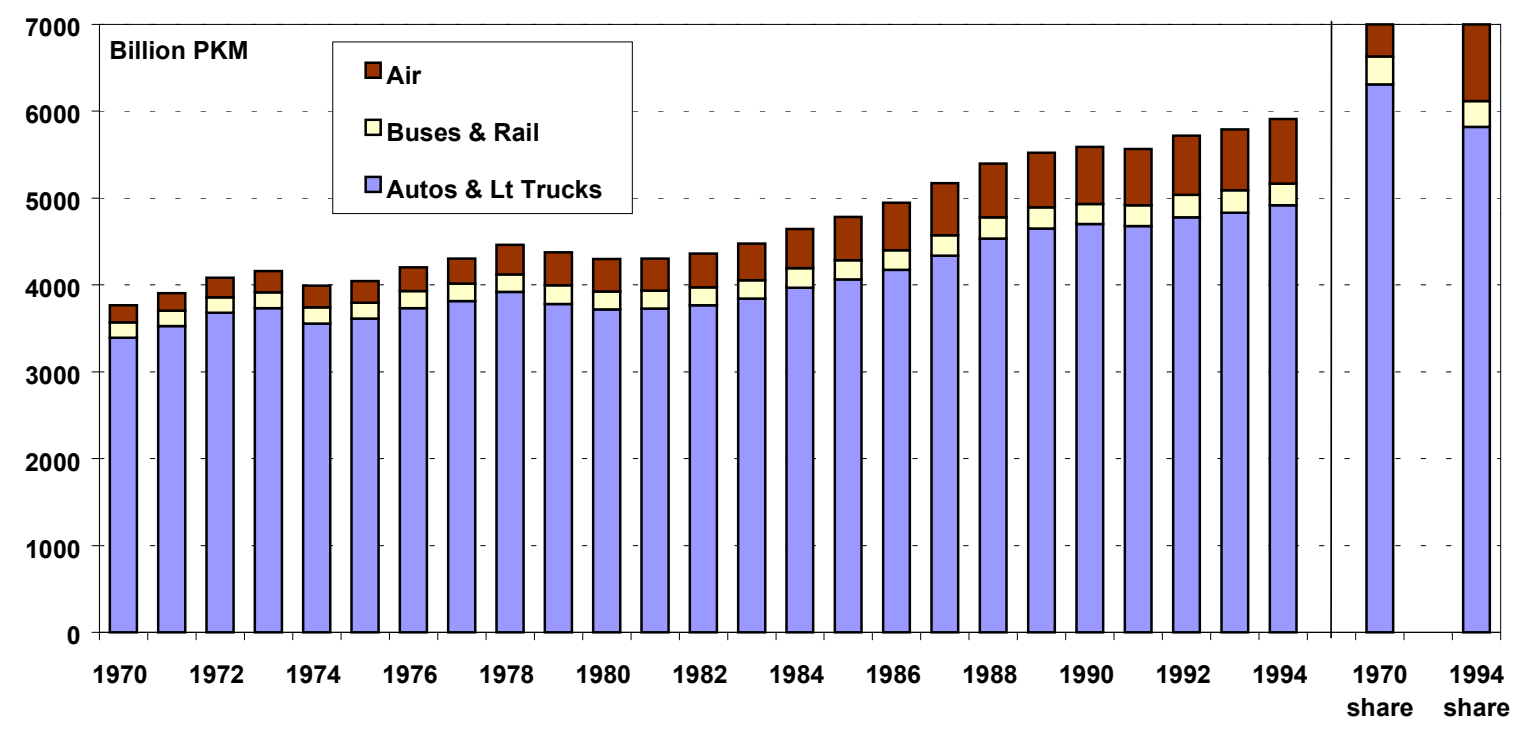

The trends in modal energy intensities, given in Figure 20, show intensities of all modes, except buses, decreased. The decline was particularly marked for air travel, where intensity fell by $55 \%$. By 1983 air travel intensity, which in 1970 was twice as intensive as auto travel, had fallen to almost the same level. The intensities of the two modes have been approximately equal ever since. Auto modal intensity fell only $8 \%$ overall and negligibly since 1990. The vehicle intensity (energy consumption per vehicle-kilometer driven) of automobiles (also shown in Figure 20) declined by about 30\% from 
1970 to 1992 and then fluctuated, as a larger share of personal vehicles counted here were vans, light trucks, and sport-utilities. The leveling off of auto vehicle intensities is not the result of reaching technical barriers. Indeed, fuel use per kilometer and kilogram of car weight has continued to fall in the 1990s, but kilograms of car have risen at about the same rate.

Figure 20. Modal Energy Intensity (Energy per PKM) by Travel Mode, with Auto Vehicle Intensity

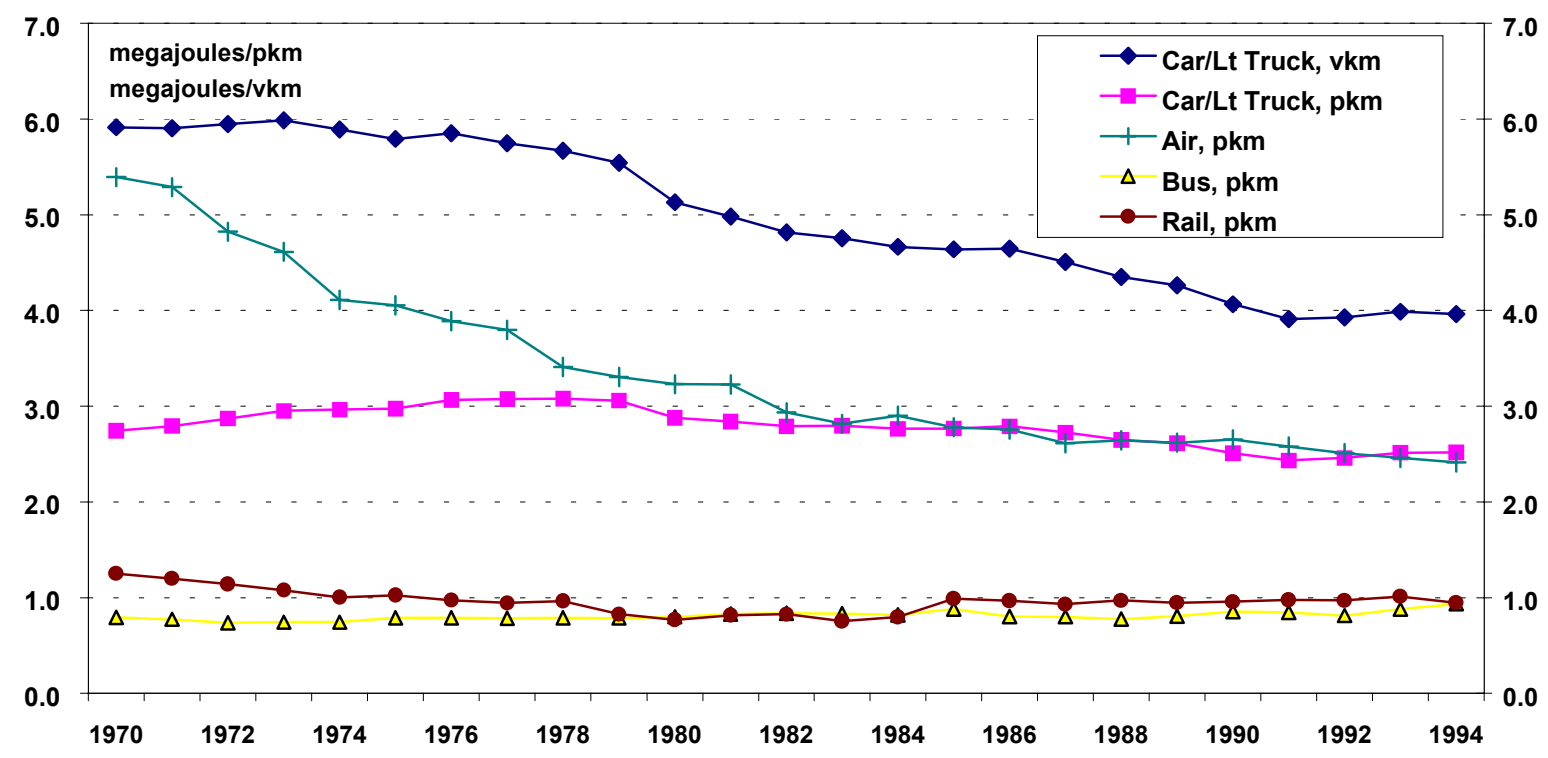

Intensity in transportation modes depends as much on the capacity utilization of each mode as it does on the technical efficiency of the vehicles per se. For example, two people riding in one car is as effective as a doubling of miles-per-gallon for two people riding in separate cars in reducing the energy consumed per pkm. As Figure 21 shows, the load factors of buses and trains have changed relatively little over time. The load factor for trains grew 10\% between 1970 and 1994 while the load factor for buses fell 6\%. Trends in these two modes offset each other to some extent, but since they only represented a little more than $4 \%$ of total pkm in 1994, the effect on total travel energy use is minimal. More importantly, the load factor for automobiles and light trucks dropped $27 \%$ over this period. This explains the difference between the changes in modal and vehicle intensities, and this trend has had a large impact on energy use. If the same total auto/light truck pkm in 1994 had been carried at the 1970 load factor, total travel energy use would have been reduced by about a quarter. This is a simplification because a higher load factor would likely result in somewhat longer trip distances (since drivers would often need to pick up or drop off one or more passengers before reaching the trip destination). However, it does indicate the large potential for ride-sharing to reduce travel energy use. 
Figure 21. Travel Load Factors by Mode

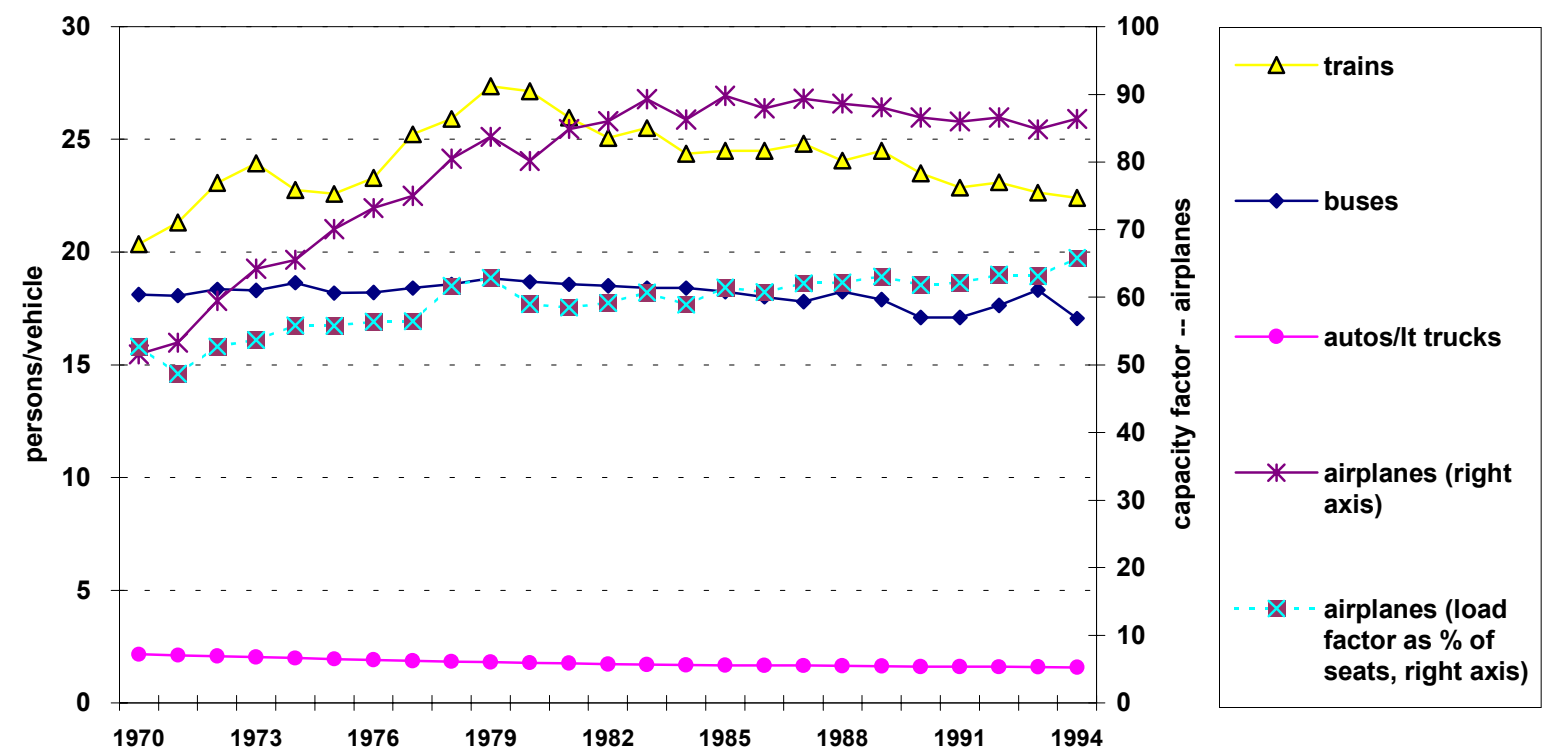

Since the load factor of airplanes is much higher than the other modes, it has been graphed on the right-hand axis of Figure 21. The load factor for airplanes is also shown as a percentage of available seats occupied because planes have simply become much larger. Contrasting the load factor measured as passengers per plane with the utilization of available seats gives a better sense of how efficiently the airline industry is using available seating capacity. Figure 21 reveals not only that airlines have improved the utilization of available seating capacity (even as seats/aircraft increased), from about $50 \%$ to $70 \%$; they have also been able to carry more people per trip due to growth in plane sizes. These two trends combined with improving technical turbine efficiencies ${ }^{\text {xvii }}$ have resulted in a dramatic decline in the modal energy intensity of air travel in the U.S.

Figure 22. Changes in Travel Energy Use: Actual and Decomposition Effects

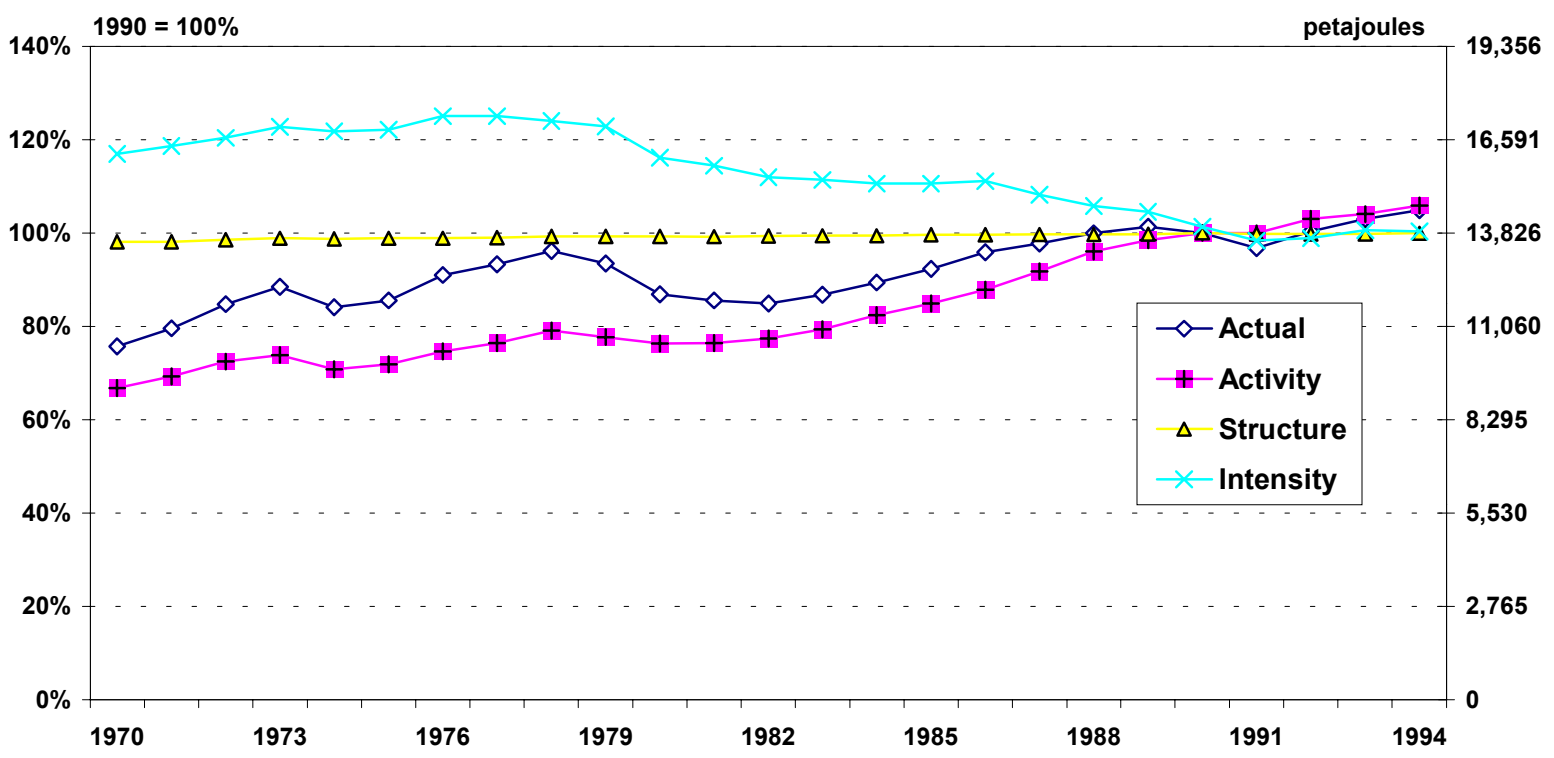

The AWD decomposition of the travel sector is shown in Figure 22. As in other sectors, falling intensities helped to offset increasing demands for energy services due to activity growth. However, 
intensity did not fall nearly as quickly as activity grew. Significant declines in energy intensity occurred only between 1979 and 1991 and have changed little since then. As noted above this is partly due to a trend toward lower capacity factors for autos and light trucks. Interestingly, the shifting shares between auto and air travel have not had much effect on energy use. The flat structure result conceals this important trend in air travel. In the earlier years, this results from the fact that air travel carries such a small share of the pkm. In later years the energy intensity of air travel versus autos and light trucks is approximately equal, and so the shifting share of pkm had little effect on the structural result. Meanwhile, the shares of pkm carried by buses and trains held remarkably steady, varying only slightly around a sum of $4.5 \%$, yielding negligible structural change.

\section{FREIGHT}

\section{Box 6. Methodology and Data Sources for the Freight Sector}

Sector end uses: Freight light and heavy trucks, domestic rail, domestic air, and domestic shipping and barges. (Pipelines are excluded.)

Activity: Freight haulage measured in metric tonne-kilometers (tkm).

Structure: The share of freight hauled in each of the modes.

Intensity: Modal intensity is energy use $/ \mathrm{km}$.

Data: Data on road vehicle-km are from the ORNL Transportation Energy Data Book, the National Transportation Statistics, and the Federal Highway Administrations Table VM-1. Data on tonne-km for interstate trucking are from the ORNL data book; data for local trucking and light trucks are estimated from Smith $1990^{\text {xxvii }}$ by taking a fixed load $(1000 \mathrm{~kg}$ for medium trucks, $200 \mathrm{~kg}$ for light trucks) at the distances driven by the medium trucks not counted in the Interstate freight statistics. Other freight vehicle and tonne-km data are taken from the ORNL data book. Energy use for air freight is estimated by David Chien of EIA. Fuel use allocations are from ORNL and the National Transportation Statistics.

Numbers, activity, and fuel use for light trucks used for freight are parsed from those used for personal travel using VIUS. See notes to preceding section.

To get a figure for energy intensity for all trucking, total energy use for all trucks (after excluding personal light trucks) is divided by both the official total tonne-km for intercity trucking and the estimates for the two other classes of trucks. The former number of tonne-km dominate the figure.

Energy use associated with freight has grown more than in any other sector, having more than doubled between 1970 and 1994. Figure 23 shows how the energy used by each mode has evolved in per capita terms. It is apparent that growth in trucking has driven most of the increase in energy use in this sector. However, in recent years, air freight has grown rapidly, although by 1994 it still accounted for less than $5 \%$ of total freight energy use. 
Figure 23. Freight Energy Use per Capita by Mode

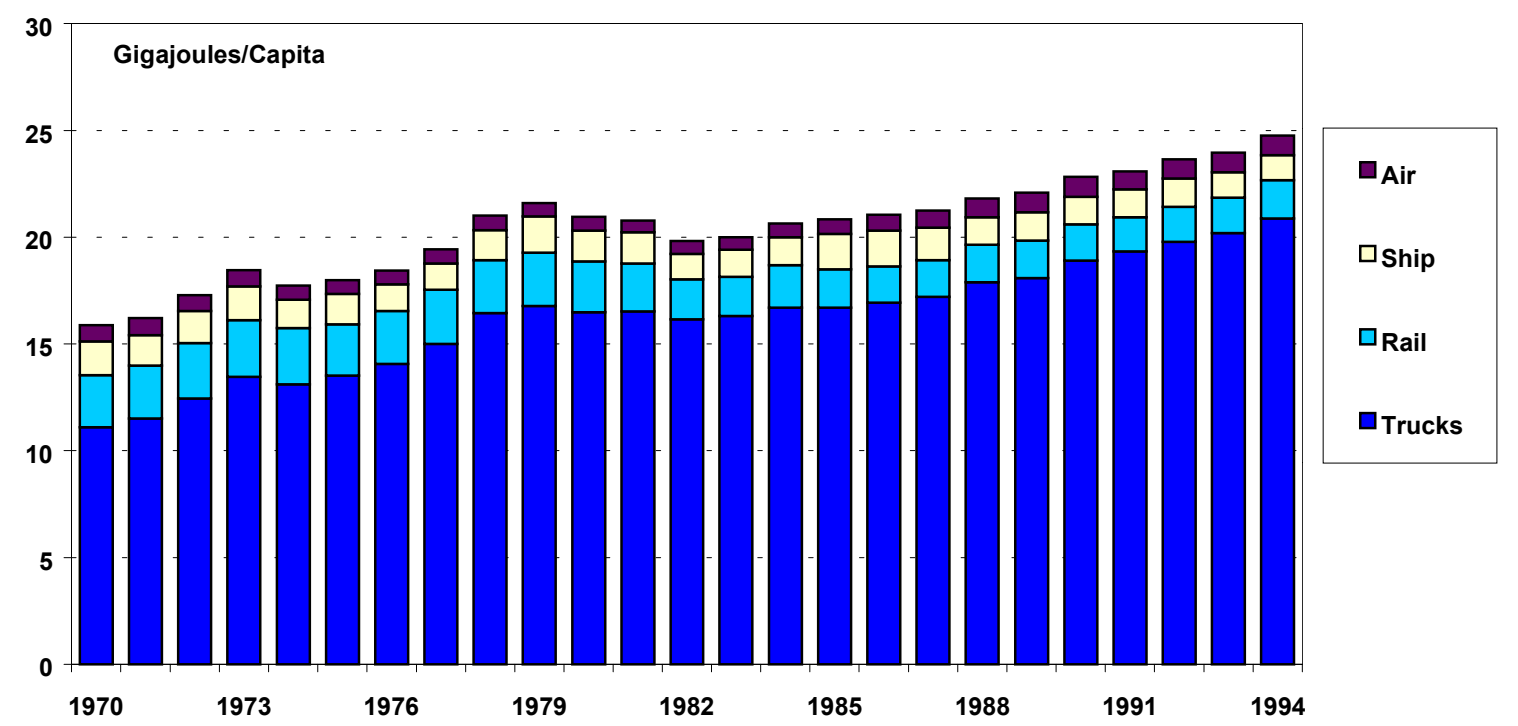

The growth in energy consumption in this sector has been fueled mostly by increasing activity. Figure 24 shows that total tkm increased rapidly from 1975 to 1980 and, after a brief decline, increased steadily since 1982 . Note that while shipping activity increased from 1970 to 1981 it has been mostly declining ever since. Interestingly, the increase in total freight haulage was less than the increase in real GDP over the same time period (73\% vs. $103 \%)$. This implies that at the economy-wide level a structural shift has occurred that saves energy per unit of GDP. Some of this decline was no doubt due to the substitution of pipeline gas (not counted) for oil or coal shipped domestically.

Figure 24. Freight Activity by Mode, with 1970 and 1994 Shares

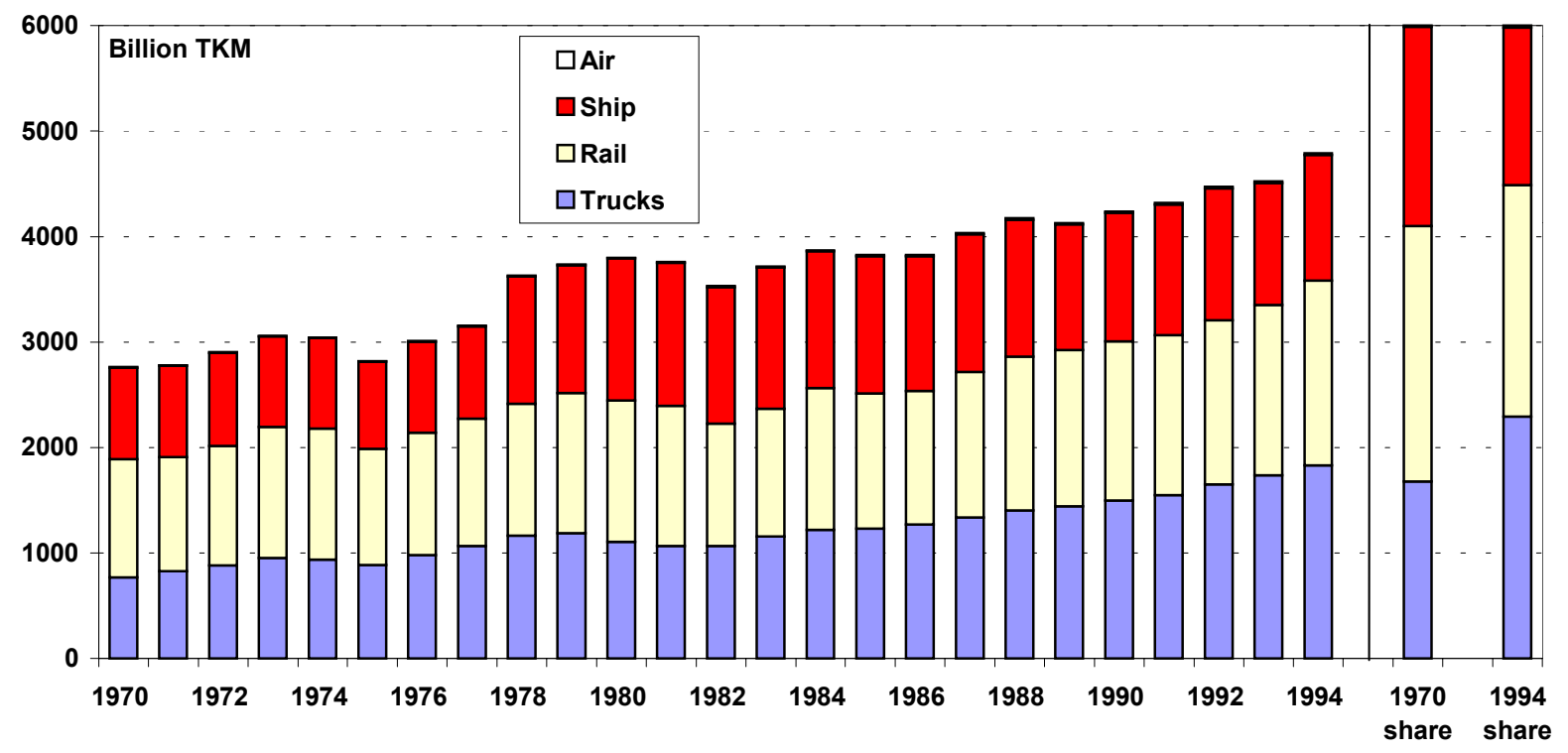

Energy consumption was also augmented by shifting modal shares. The last two bars in Figure 24 show that trucking has captured market share, largely at the expense of shipping. The increasing share of trucking, something seen in most IEA member countries, is the principal reason for this aggregate increase in the energy intensity of freight. Since energy intensities in freight vary more widely across 
modes than in travel modes (from $12 \mathrm{MJ} / \mathrm{tkm}$ for air to $0.25 \mathrm{MJ} / \mathrm{tkm}$ for rail), structural changes have a larger effect on freight energy use. Since trucking dominates energy use in freight, the decomposition results are largely the result of the evolution of this mode. While activity for all modes has increased, it has increased much faster for trucking and air freight. In relative terms air freight has increased the most. However, despite a four-fold increase in air freight since 1970, it does not account for a large enough share to have had much effect on the decomposition results. ${ }^{11}$

The energy intensity effect has been relatively modest in this sector. This results from the fact that trucking dominates energy use in the sector and trucking intensity declined only slightly overall (see Figure 25). Trucking intensity actually increased from 1970 to the mid-1980s but then declined substantially from 1982 to 1992 . Part of the reason for this increase may be explained by the decrease in the load factor during the 1970s. Between 1970 and 1981 the average vehicle load dropped from 3.9 tons/truck to 3.0 tons/truck, a figure around which the vehicle load has hovered ever since. Some of this decline in loading was probably due to the rise of local trucking and distribution of goods. That intensity continued to decrease is explained best by technical factors. Since trucking was decontrolled beginning in 1978, one result may have been first an increase in intensities, which turned to a rather dramatic decrease after 1985.

\section{Figure 25. Freight Modal Intensities}

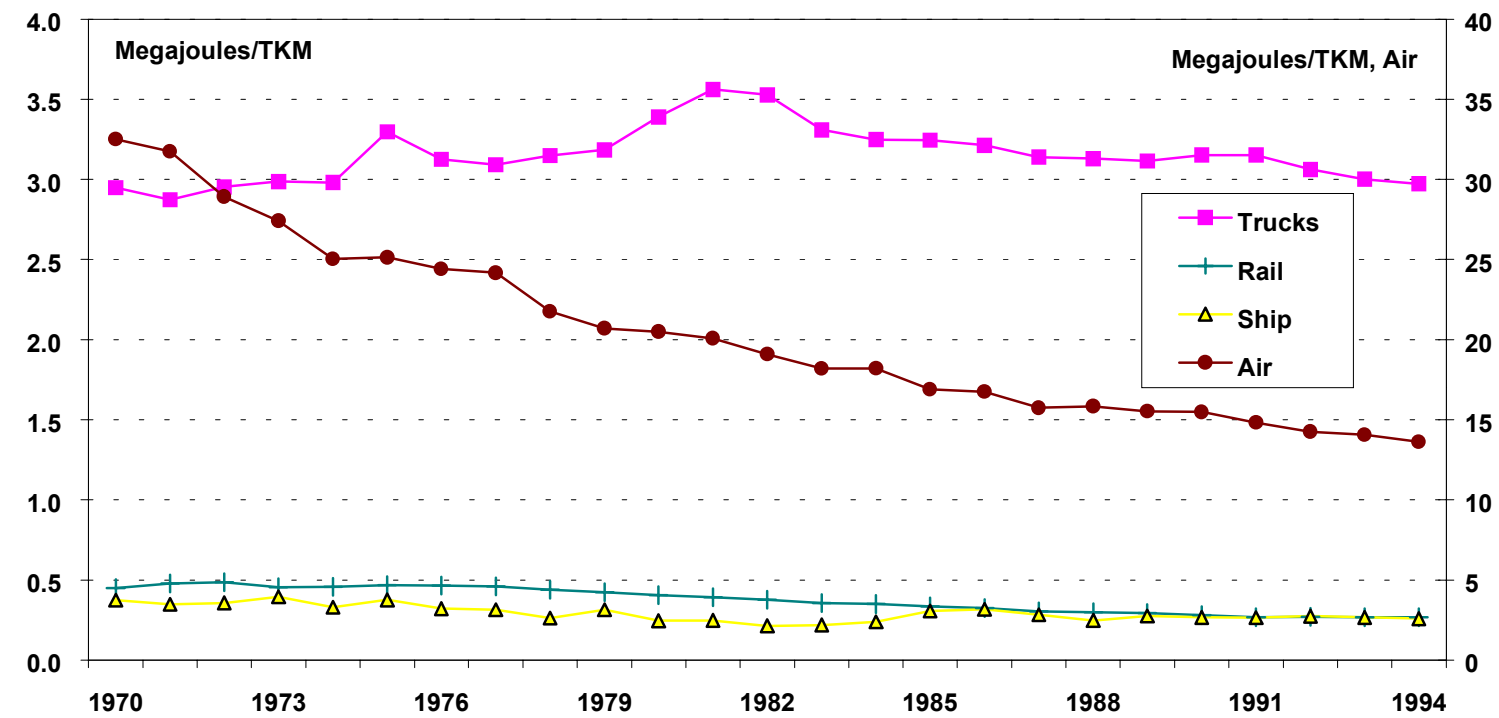

Intensities of the other modes decreased much more than it did for trucking. The freight train load factor increased by about two-thirds to over 38 tons per car. This undoubtedly explains much of the $40 \%$ decline in rail intensity. Air freight experienced the largest decline, with the modal intensity falling 58\%. Increasing load factors, pushed up in part by growth in airplane sizes, probably contributed to the change in intensity for air freight as it did for passenger air energy use. Unfortunately sufficient data to determine vehicle loads are only available for freight trains. Shipping intensity also declined, by $30 \%$, although shipping intensity has not changed much since the late 1970 s and is about the same now as it was in the mid 1960s.

\footnotetext{
${ }^{11}$ Estimates of air freight energy were provided by David Chien of EIA from his historical analysis and model. These were subtracted from total domestic commercial aviation fuel use.
} 
Figure 26. Changes in Freight Energy Use: Actual and Decomposition Effects

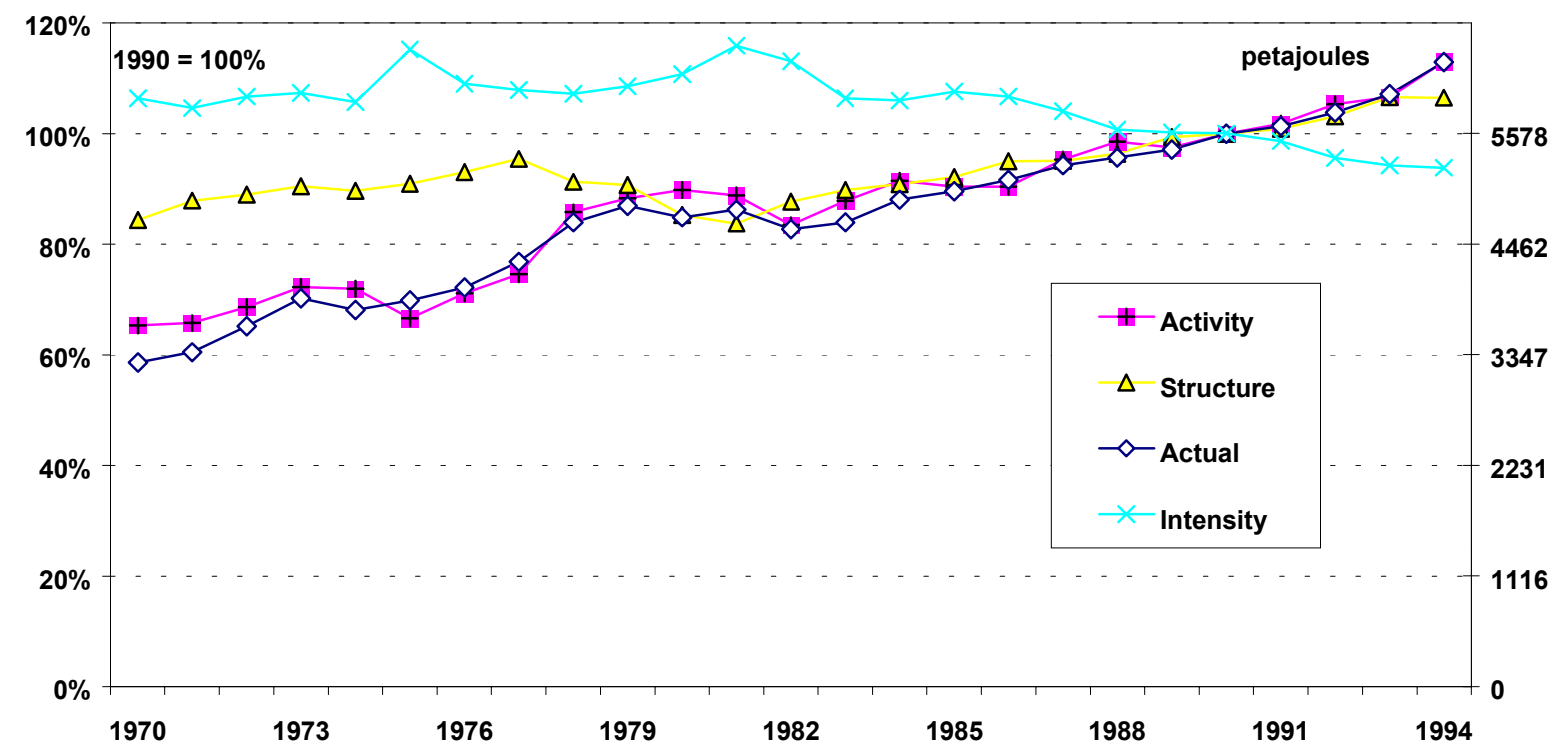

The decomposition results summarize the effects of these changes on total freight delivered energy use. The structural and intensity effects have largely negated each other in this sector, leading to the close correlation between activity and energy use. What is interesting in this sector is that relatively little energy savings have resulted from intensity changes compared to the other sectors. As discussed above, this has largely been the product of decreasing load factors for trucking. However, as that trend leveled off after 1980, improvements in technical and/or distribution efficiencies began to yield decreasing intensity per tkm. 


\section{ALL-SECTOR RESULTS}

How did the U.S. energy economy perform overall? Combining sectoral decomposition results provides one answer. This is done by using the decomposition results for each term, expressed in energy units, using 1990 as a base year. The results by sector (for a given component) are then summed for each year to estimate the total energy use as determined by each decomposition term. The results can also be expressed as an index by dividing each year's result by the 1990 total energy use for the six sectors studied. The all-sector summation of our decompositions is shown in Figure 27.

Figure 27. All-Sector Sum of Decomposition Results

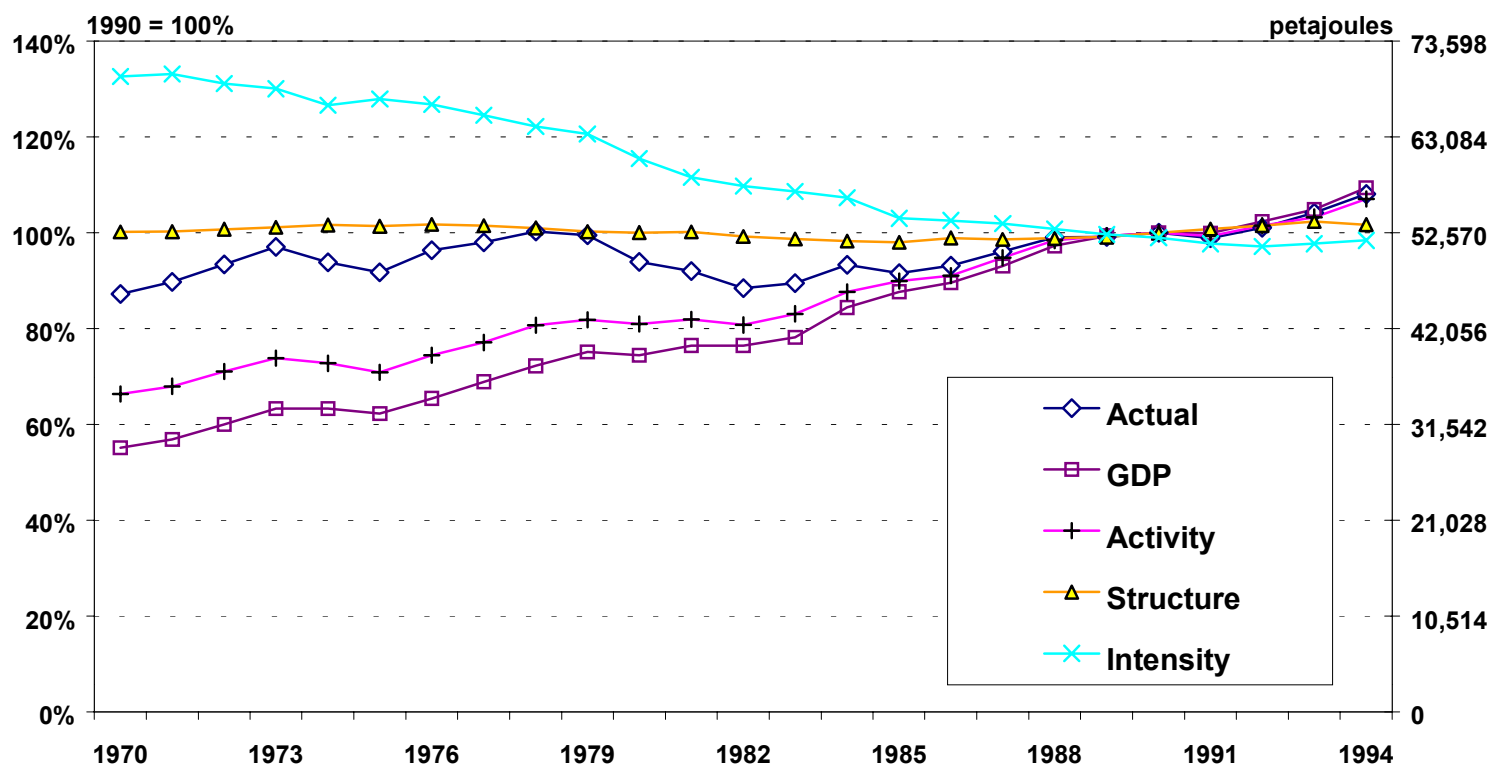

While overall energy use only increased about 20\% from 1970 to 1994, virtually all of that increase has happened since 1985. If energy use had grown continuously at the rate it did since 1985, total energy use would have increased by over half. In this figure we also include the GDP effect, which simply indexes real GDP in 1990 dollars. This shows how energy use would have evolved at a constant E/GDP ratio. Recall that the activity effect for all sectors combines value added with physical indicators for travel, freight, and residential sectors. The fact that the activity indicator has grown less quickly than GDP indicates a structural shift at the economy-wide level that contributes to energy savings.

It is also interesting to note how little impact structural changes have had in changing total energy use. Table 5 lists the contributions to energy savings in each sector from the structure effect and other decomposition terms. This shows that structural changes have had large impacts on energy use for several sectors. However, increased energy use from structural changes in freight, residential and travel was offset by the decrease in manufacturing energy use that resulted from the shift toward lighter industries and the declining amount of floor space used per unit of value added in the service sector. 
Table 5. Difference in Delivered Energy Consumption (PJ) in 1994 vs. 1970 by Decomposition Term $^{1}$

\begin{tabular}{|l|r|r|r|r|r|r|}
\hline Sector & $\mathbf{1 9 7 0}$ Actual & $\begin{array}{c}\text { Difference, } \\
\text { 1994-1970 }\end{array}$ & Activity & Structure & $\begin{array}{c}\text { Energy } \\
\text { Services }\end{array}$ & Intensity \\
\hline Manufacturing & 13,193 & 61 & 6,632 & $-2,804$ & 5,172 & $-7,044$ \\
Other Industries & 3,494 & 150 & 958 & 165 & 1,088 & $-1,188$ \\
Services & 5,081 & 1,776 & 3,640 & $-1,524$ & 2,807 & $-1,619$ \\
Residences & 9,738 & 855 & 2,325 & 2,382 & 4,373 & $-4,845$ \\
Travel & 10,577 & 3,909 & 5,303 & 224 & 5,451 & $-2,261$ \\
Freight & 3,283 & 3,196 & 2,741 & 1,295 & 3,753 & -625 \\
All sectors & 45,366 & 9,947 & 21,600 & -263 & 21,798 & $-17,582$ \\
\hline
\end{tabular}

${ }^{1}$ Figures in this table represent the change in annual energy consumption attributed to each decomposition term. Thus, the manufacturing sector used 61 more PJ in 1994 than in 1970, but if value added had grown as it did with no structure or intensity changes, it would have consumed 6,632 more PJ. Since the decomposition methodology is multiplicative, the results are not additive across terms.

The big story, however, is the extent to which decreases in energy intensity offset the upward pressure on demand for energy services. Activity growth in manufacturing, travel, freight, and services all placed strong upward pressures on energy use, while improvements in energy intensity occurred for several subsectors and end-uses. In manufacturing the greatest declines occurred in chemicals, nonmetallic minerals, nonferrous metals, and light manufacturing. However, the result in light manufacturing may be largely the result of structural shifts within this category. Travel intensities for air and rail modes declined dramatically. This is due largely to increased load factors, and for airplanes, improvements in airplane design and turbine efficiency. Intensity indicators for cars and light trucks however, changed little over the study period. While significant fuel economy improvements did occur (the fleet in 1995 used approximately 30\% less fuel $/ \mathrm{km}$ than in 1973), the load factor fell from 2.2 persons per trip to slightly less than 1.6. In percentage terms, the drop in load factor nearly offset the drop in fuel intensity, so that the energy required to transport a person one $\mathrm{km}$ by car only fell slightly. Since cars and light trucks account for the bulk of pkm for the travel sector, overall the modal energy intensity of travel fell only slightly. Freight intensities for air, rail, and ships all declined. As in the travel sector however, the most important mode changed little: trucking intensity declined by less than one percent from 1970 to 1997.

In the residential sector most end-uses showed significant improvements. Space heating energy intensity declined by nearly half, while intensities of water heaters, washing machines, and dryers were the only intensities to decline little or not at all. For services, since energy consumption data are not disaggregated down to more than a few end-uses it is difficult to say what drove intensity down. It is likely that heating and cooling efficiency were the major drivers.

Figure 28 puts a number of the key intensities into index form, base 1990. It is clear that air travel had the largest decline, followed closely by home heating and manufacturing, then automobile vehicle intensity. Since 1990, air travel and home heating intensities, as well as those of major appliances, continue to decline, while automobiles and manufacturing have leveled off. 
Figure 28. Changes in Key Intensities, Indexed to 1990

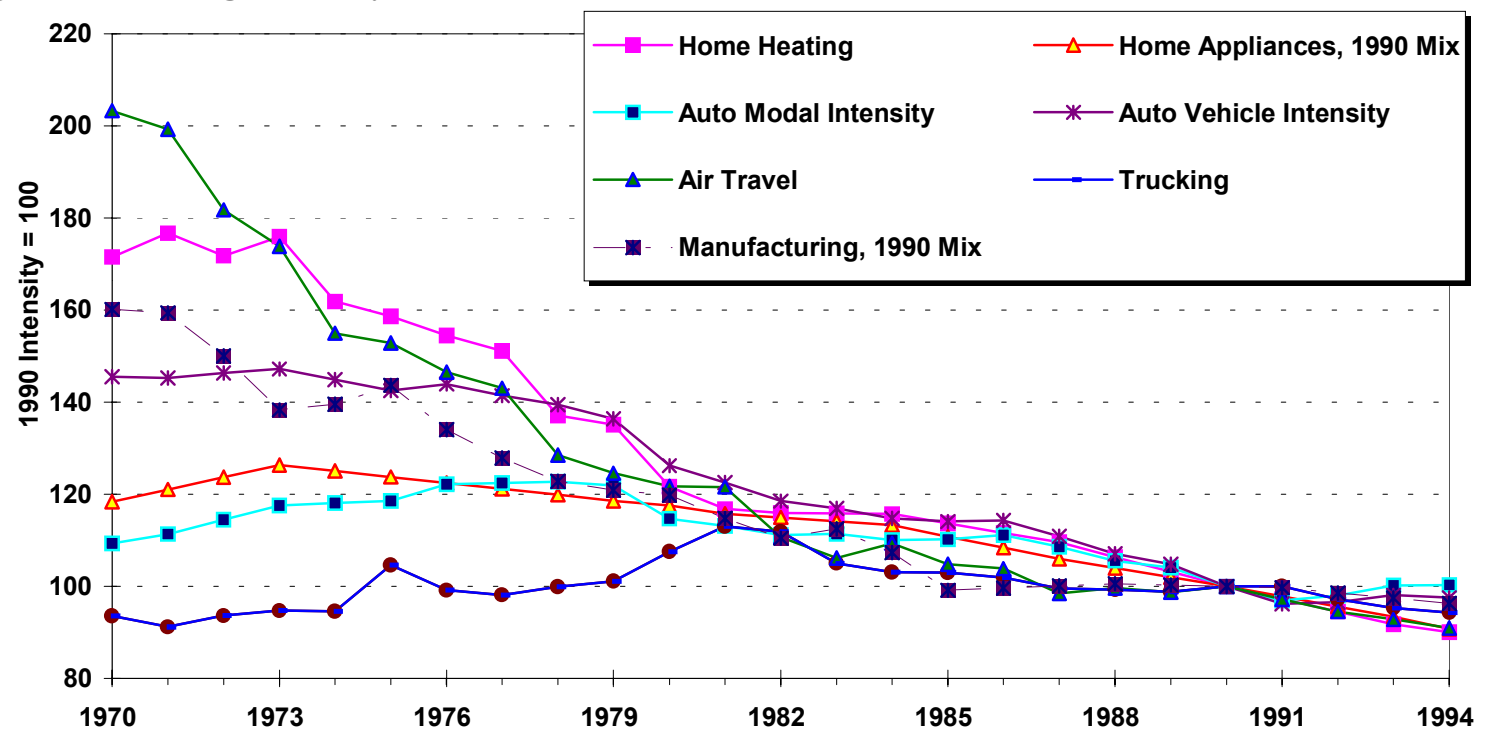

Energy services showed strong increases as a result mostly of activity growth. Comparing this with GDP, however, yields a very important result. The overall change in the quotient of these two indicators measures whether the structure of the economy overall has become more or less energy intensive. From 1973 to 1985 this quotient went from 115 to 100, while it was relatively stable before 1973 and after 1985. The fact that the period of greatest change coincides with the era of high real energy prices suggests, but does not prove, that high fuel prices were one cause of the structural changes. At the same time, the fact that there was little rebound in intensities after the mid-1980s suggests that other forces were also important in reducing the energy intensity of the U.S. economy besides fuel prices. The upturn in manufacturing intensities and the leveling of those for automobiles and personal light trucks are troubling since these two sectors contributed significantly to overall energy savings between 1973 and 1990.

Figure 29 shows the savings in primary energy use in the U.S. in 1994 from changes in energy intensity since 1973 . The estimate multiplies 1973 primary energy consumption by the ratio of the 1994 index of energy services to the 1973 index, thereby leaving the intensities unchanged. The differences are shown as savings in the figure. As can be seen, these are substantial, adding up to $15,000 \mathrm{PJ}$ in 1994, roughly $30 \%$ of the actual primary energy consumption. Put another way, without the savings in energy, U.S. consumption would have been 30\% higher than it actually was in 1994. While this calculation ignores the impact that the savings of energy had on energy prices and consequent rebound effect on consumption, it shows how profound the overall impact of energy saving has been. 
Figure 29. Sector by Sector and Total 1994 Savings in Primary Energy Use, Actual Energy Use Compared to Hypothetical Consumption at 1973 Intensities

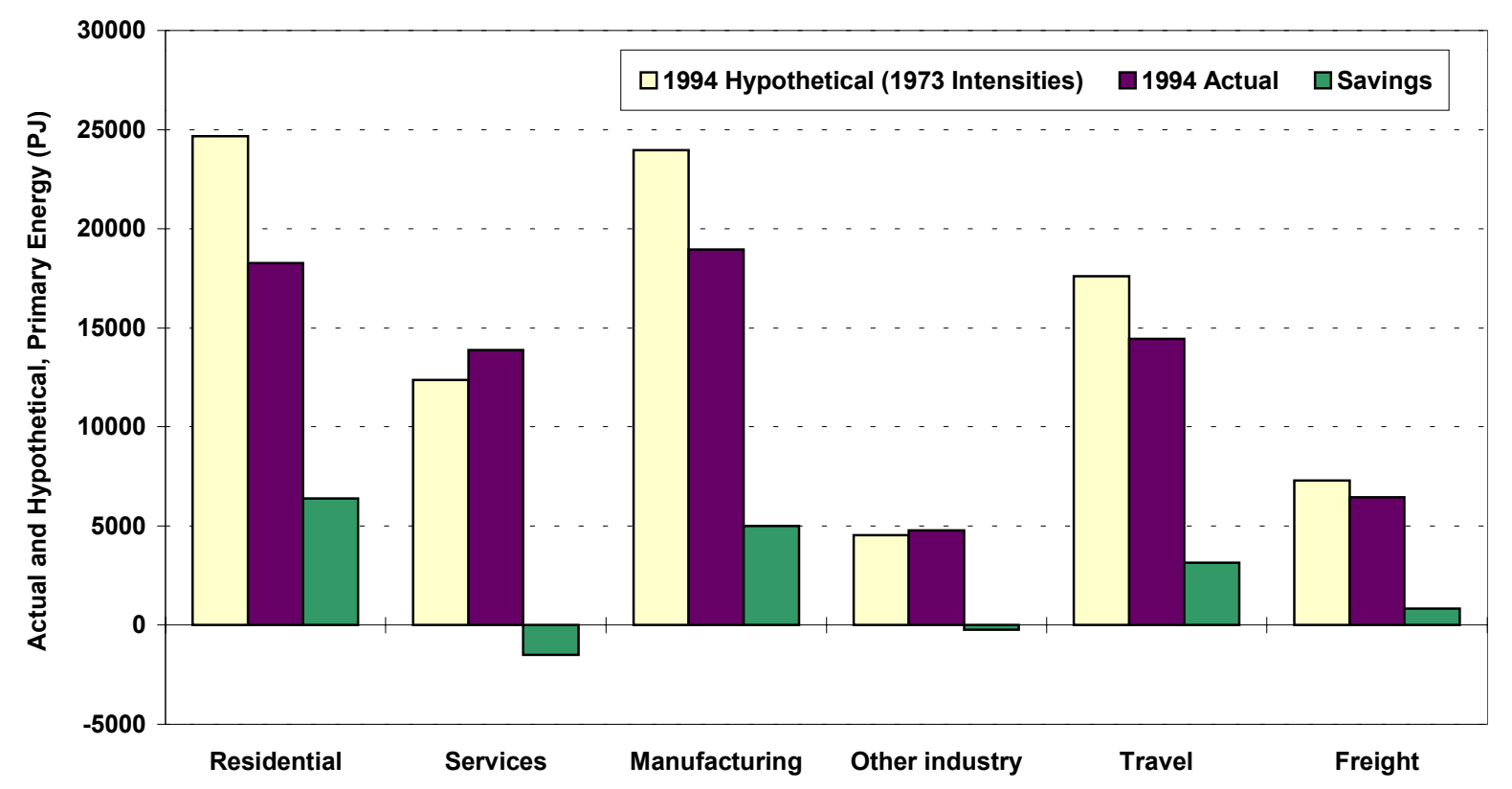

Figure 30 shows the average annual rates of change in the key components of U.S. energy use from 1973 to 1994, broken into key periods. Several very important conclusions spring from both the differences among each component and the contrasts in the behavior during the two periods.

- Before 1985, GDP grew much faster than energy use. Note how delivered energy fell 1973 to 1985 , while GDP grew by nearly $3 \%$ per year. If we portrayed primary energy in the six main sectors, growth was about $0.6 \%$ per year, still very low relative to the GDP growth indicated. But after 1985 , delivered energy grew at nearly $2 \%$ per year (and primary at $2.4 \%$ per year) while GDP grew at $2.5 \%$ per year. The delivered E/GDP ratio fell by more than $3 \%$ per year in the first period, but only by $0.5 \%$ per year after 1985 (primary only by $0.1 \%$ per year).

- Before 1985, demand for energy services fell relative to GDP. The ratio of changes in the index of energy services to GDP fell by over $1 \%$ annually in the first period but by less than $0.1 \%$ per year in the second period. This suggests that the U.S. economy was undergoing structural changes (making it less energy intensive) that were stimulated by higher energy prices, changes which nearly halted after 1985 .

- Energy intensities continued to fall after 1985, but the rate of decline slowed markedly. The index of all energy intensities fell by almost $1.7 \%$ per year between 1973 and 1985 , but only by $0.5 \%$ per year thereafter. This is more direct evidence of the slow-down in the rate of energy saving. Note that using this index, however, that slowdown was only $1.5 \%$ per year. By contrast, the change in the decline of the ratio of energy use to GDP was much greater, by more than $2 \%$ per year between the first and second periods. The slowdown in energy saving in the U.S. economy after 1985 was real, but not as dramatic if measured sector by sector and use by use with indices than if represented by the ratio of energy use to GDP.

- While most of the decline in E/GDP between 1973 and 1985 was due to reduced energy intensities, structural changes contributed significantly. Of the overall decline in energy use to GDP from 1973 to 1985 , roughly $2 / 3$ was energy saving and 1/3 was structural savings. 
Thereafter structural changes contributed almost nothing to energy saving, while falling intensities continued to restrain growth in energy use. If some of the structural changes in the first period reversed (those in the manufacturing sector did to some extent), then this change in the role of structural changes is not surprising.

- Demand for energy services increased at approximately the same rate as GDP both before and after the 1973 - 1985 period. From 1965 to 1973, the overall growth in GDP was 3.9\% per year. The energy services term (measured using Laspeyres indices) grew by $3.6 \%$ per year in final energy terms and $4 \%$ per year in primary energy terms. (The difference indicates that electricityintensive activities grew more rapidly than those predominately based on fuels, mostly because of growth in the household and commercial/service sector.) From 1973 to 1985, energy services lagged GDP growth by around 1.2\% per year, but from 1985 to 1994 this difference fell to only $0.2 \%$ per year, and in both periods primary and final energy services grew at nearly the same rates. Thus the important structural changes that occurred between 1973 and 1985 were not part of a longer term trend, at least when the entire period 1965-1994 is considered using somewhat different indices. This adds to the weight of evidence that the structural changes in the middle period were accelerated by the higher energy prices that marked this period.

Figure 30. Average Annual Rates of Growth of All-Sector Decomposition Terms, 73-85 vs. 8594

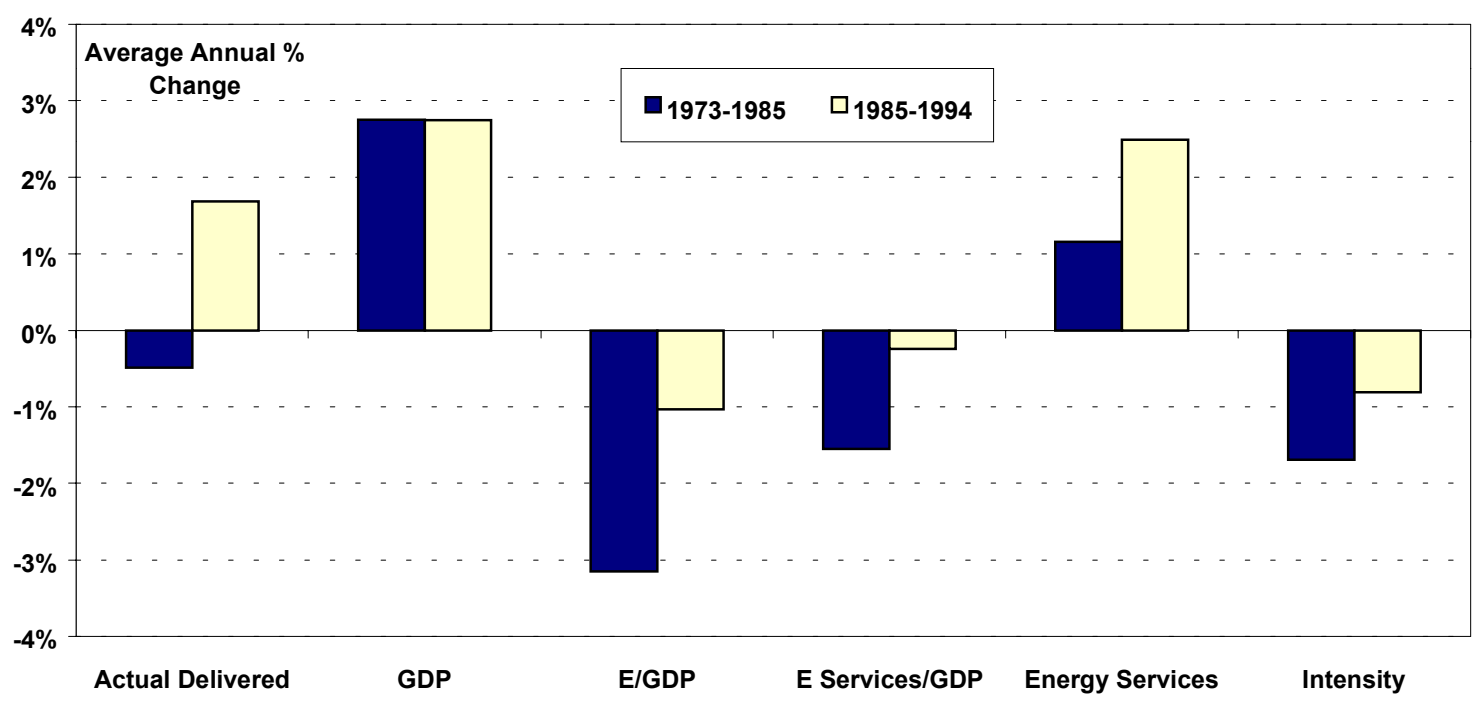




\section{CONCLUSIONS}

Several factors have affected the patterns of American energy consumption over the period of this study. In the sectors considered here, total delivered energy use rose by 22 percent, while the total GDP doubled. Thus, the amount of delivered electricity used per GDP fell dramatically. This was not true for all energy sources. Electrification of the U.S. economy continued to progress, as the rate of electricity consumption per GDP remained steady. Since the share of electricity rose (from 11 percent to 18 percent of delivered energy), and electricity production is associated with large losses of primary energy, total primary energy consumption increased almost twice as much as delivered energy.

Untangling the effects that underlying factors have had on historical trends of energy consumption is a complicated task. In our approach, we have disaggregated U.S. energy consumption into thirty key end uses in six end-using sectors. Using decomposition indices, we allocated the changes to activity, structure, and intensity terms. Our analysis shows that overall, reductions in energy intensity decreased energy use by 26 percent in 1994 compared to 1970 intensities. However, growth in activity levels raised energy consumption by 62 percent. Structural changes toward greater energy consumption in the freight and residential sectors offset shifts toward lower consumption in manufacturing and services, resulting in almost no net effect attributable to the structure term.

The specific end-uses and that have experienced the largest relative gains in energy use are trucking, air travel, and electric end-uses in the service sector. In contrast, total energy consumption for manufacturing (particularly heavy manufacturing) and residential space heating remained steady or fell.

When energy use is compared to changes in GDP, changes in demand for energy services relative to GDP introduce another element of structural change. Since activity indicators rose by only 62 percent while the GDP doubled, this indicates saturation of some energy-consuming activities relative to GDP. Indeed, this phenomenon was almost as important in lowering the E/GDP ratio as decreases in energy intensities were. However, our time series analysis has also shown that patterns of energy use changed significantly with the sharp drop in energy prices. Between 1985 and 1994, the annual rate of decline in the E/GDP ratio fell from over three percent to about one percent. This occurred both because demand for energy services increased and intensities began to fall more slowly. 


\section{ACKNOWLEDGEMENTS}

The authors would like to thank Mary Beth Zimmerman of the Office of Energy Efficiency and Renewable Energy of the Department of Energy for funding this work. We also gratefully acknowledge the helpful comments of Jon Koomey and Ernst Worrell at the Berkeley Lab. Scott Murtishaw thanks the International Energy Agency for hosting him during part of the time this study was conducted.

\section{Disclaimer}

This document was prepared as an account of work sponsored by the United States Government. While this document is believed to contain correct information, neither the United States Government nor any agency thereof, nor The Regents of the University of California, nor any of their employees, makes any warranty, express or implied, or assumes any legal responsibility for the accuracy, completeness, or usefulness of any information, apparatus, product, or process disclosed, or represents that its use would not infringe privately owned rights. Reference herein to any specific commercial product, process, or service by its trade name, trademark, manufacturer, or otherwise, does not necessarily constitute or imply its endorsement, recommendation, or favoring by the United States Government or any agency thereof, or The Regents of the University of California. The views and opinions of authors expressed herein do not necessarily state or reflect those of the United States Government or any agency thereof, or The Regents of the University of California. 


\section{APPENDIX. COMPARISON TO THE 1995 ENERGY CONSERVATION TRENDS REPORT (DOE/PO-0034)}

The work presented in this report differs methodologically in several respects from Energy Conservation Trends (ECT), the previous comprehensive study of U.S energy conservation (see endnote i). Both reports use a Divisia decomposition of the industry and transport sectors, although the specifications differ slightly. More significantly, the definitions of the sectors and the identity used to decompose delivered energy consumption differ.

In the industry sector we analyze the effects separately for manufacturing and non-manufacturing industries, since we view these as fundamentally different activities. Moreover, the data quality of the non-manufacturing industries is less reliable. Beyond this basic difference in the composition of the sector, we have used another arrangement of the identity to decompose energy use. We have disaggregated manufacturing into six sectors (which account for over $75 \%$ of manufacturing energy use in 1994) and an "other manufacturing" grouping of the remaining industries, while ECT breaks manufacturing down into sixty-eight industry branches and nests the structural effect at four separate levels of industry grouping.

In the transportation sector the approaches used are quite similar. The most important distinction between the two studies is that ECT disaggregates intensity into two terms: vehicle efficiency and load factor. In passenger transportation ECT also differentiates light trucks from cars as a separate travel mode. For freight we have made an estimate of energy use and tkm for air freight hauled on both commercial passenger and cargo flights, enabling us to include air freight as another mode where the previous report did not.

Fundamental methodological differences occur in the buildings sectors, most importantly for residential buildings. Key differences in both the residential and commercial sectors are that ECT defines "activity" as household and commercial floor space while this study uses population and services value added. We then use floor space per capita or per services value added as the structure terms for our decompositions. Neither of these approaches constitutes a true structural disaggregation in the sense that these terms do not measure subsectoral shares of activity. However, by redefining the structural parameter we are able to use a Divisia decomposition for these sectors, while other statistical methods were employed in ECT. ECT defines residential energy intensity as energy per household. The authors then use a regression analysis on monthly electricity and natural gas consumption to divide energy use into weather and non-weather sensitive components of energy use. Energy savings are calculated separately for heating, cooling, and baseline energy uses. However, this method does not control for the crucial structural changes that we note in our report: increasing floor space per capita, increasing saturation of appliances, and a declining number of occupants per household. Additionally, ECT counts electrification of space heating as a savings of delivered energy (since the delivered energy is more efficiently converted to heat), whereas this report uses useful energy intensities to control for fuel-switching. 


\section{Endnotes}

${ }^{\mathrm{i}}$ Belzer, D, J Roop, R Sands, and DL Greene. 1995. Energy Conservation Trends, Energy Efficiency in the U.S. Economy, Report Three, U.S. Department of Energy, Office of Energy Efficiency and Alternative Fuels Policy, Washington, DC. DOE/PO-0034

ii Energy Information Administration. State Energy Data Reports. Washington, DC: U.S. Dept. of Energy, EIA.

iii Schipper LJ, R Steiner, P Duerr, and S Strom. 1992. Energy Use in Passenger Transport in OECD Countries: Changes between 1970 and 1987, Transportation, 19 25-42

${ }^{\text {iv }}$ Boyd G, JF Mcdonald, M Ross, and DD Hanson. 1987. Separating the changing composition of U.S. manufacturing production from energy efficiency improvements: A Divisia index approach , Energy Journal, Vol. 8, No. 2, April, 77-96.

Greening, LA, WB Davis, LJ Schipper, and M Khrushch. 1997. Comparison of Six Decomposition Methods: Application to Energy Intensity for Manufacturing in Ten OECD Countries. Energy Economics 19(3): 375-390. Howarth R and LJ Schipper. 1992. Manufacturing Energy Use in Eight OECD Countries: Trends through 1988

- Decomposing the Impacts of Changes in Output, Industry Structure and Energy Intensity. The Energy

Journal, 12(4): 15-40.

Liu XQ, BW Ang, and HL Ong. 1992. The application of the Divisia index to the decomposition of changes in industrial energy consumption, Energy Journal, Vol. 13, No. 4, December, 161-177

${ }^{v}$ Murtishaw, S., L Schipper, F Unander, S Karbuz, and M Khrushch. 2000. Lost Carbon Emissions: The Role of Non-Manufacturing "Other Industries" and Refining in Industrial Energy Use and Carbon Emissions in IEA Countries. Energy Policy 29(2): 83-102

${ }^{v i}$ Schipper LJ, R Haas, and DC Sheinbaum. 1996. Recent Trends in Residential Energy Use in OECD

Countries and their Impact on Carbon Dioxide Emissions: A Comparative Analysis of the Period 1973-1992, Mitigation and Adaptation Strategies for Global Change

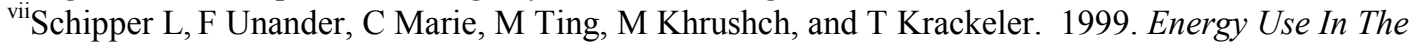
Netherlands In An International Perspective: Comparison Of Trends Through The Mid-1990s. Paris: Int'l Energy Agency.

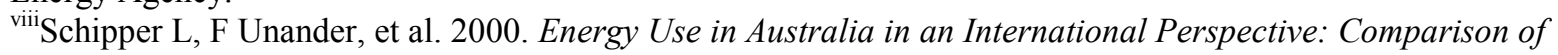
Trends Through the Mid 1990s. Paris: Int'l Energy Agency

${ }^{\mathrm{ix}}$ Schipper LJ, F Unander, and C Marie. 1999. One Man's Carbon is Another Man's Bread: Understanding Differences in the Structure of Carbon Emissions. Proc. International Association of Energy Economics, Rome 9-12 June 1999. LBNL-43759

${ }^{\mathrm{x}}$ U.S. Bureau of Economic Analysis. 2000. Gross Domestic Product by Industry. http://www.bea.doc.gov/bea/dn2/gpo.htm

${ }^{x i}$ Energy Information Administration. Manufacturing Energy Consumption Surveys. Washington, DC: U.S. Dept. of Energy, EIA.

xii Energy Information Administration. Annual Energy Outlook. Washington, DC: U.S. Dept. of Energy, EIA.

xiii Energy Information Administration. Commercial Building Energy Consumption Surveys. Washington, DC: U.S. Dept. of Energy, EIA.

xiv Belzer, DB, LE Wrench, and TL Marsh. 1993. End-Use Energy Consumption Estimates for U.S. Commercial Buildings, 1989. Richland, WA: Pacific Northwest National Laboratory. PNL-8946.

${ }^{\mathrm{xv}}$ Bureau of the Census. American Housing Survey. Washington, DC: U.S. Dept. of Commerce, Bureau of the Census.

${ }^{\text {xvi }}$ Energy Information Administration. Residential Energy Consumption Surveys. Washington, DC: U.S. Dept. of Energy, EIA.

xvii Dole, SH. 1975. Energy Use and Conservation in the Residential Sector: A Regional Analysis. Santa Monica, CA: Rand Corporation R-1641-NSF

xviii Newman, DK and D Day. 1975. The American Energy Consumer: A Report to the Energy Policy Project of the Ford Foundation. Cambridge, Mass.: Ballinger Pub. Co.

${ }^{\text {xix }}$ Schipper, L, S Bartlett, D Hawk, and E Vine. 1989 "Linking Life-Styles and Energy Use: A Matter of Time?" Annual Review of Energy, 14: 273-320.

${ }^{x x}$ Schipper, L, A Ketoff, and A Kahane. 1985. "Explaining Residential Energy Use by International Bottom-Up Comparisons," Annual Review of Energy, 10:341-405.

${ }^{\mathrm{xxi}}$ Sanchez, MC, JG Koomey, MM Moezzi, A Meier and W Huber. 1998. "Miscellaneous Electricity in US Homes: Historical Decomposition and Future Trends.” Energy Policy 26 (8): 585-593.

xxii Oak Ridge National Laboratory. 1976-2000. Transportation Energy Data Book. www-cta.ornl.gov/data 


\footnotetext{
xxiii Bureau of Transportation Statistics. National Transportation Statistics. Washington, DC: U.S. Dept of Transportation, Bureau of Transportation Statistics.

${ }^{\text {xxiv }}$ Federal Highway Administration. Nationwide Personal Transportation Survey. Washington, DC: U.S. Dept. of Transportation.

${ }^{x x v}$ Mutch, JJ. 1973. Transportation Energy Use in the United States: A Statistical History, 1955-1971. Santa Monica, CA: Rand Corporation R-1360-NSF

xxvi Bureau of the Census. Vehicle Inventory and Use Survey. Washington, DC: U.S. Dept. of Commerce, Bureau of the Census.

xxvii Green, DL. 1992. Energy Efficiency Improvement Potential of Commercial Aircraft. Annual Review of Energy and the Environment 17: 537-73.

xxviii Smith, FA. 1990. Transportation in America: A Statistical Analysis of Transportation in the United States. Washington, DC: Eno Foundation for Transportation.
} 